\title{
Reactions to Discrimination, Stigmatization, Ostracism, and Other Forms of Interpersonal Rejection: A Multimotive Model
}

\author{
Laura Smart Richman and Mark R. Leary \\ Duke University
}

\begin{abstract}
This article describes a new model that provides a framework for understanding people's reactions to threats to social acceptance and belonging as they occur in the context of diverse phenomena such as rejection, discrimination, ostracism, betrayal, and stigmatization. People's immediate reactions are quite similar across different forms of rejection in terms of negative affect and lowered self-esteem. However, following these immediate responses, people's reactions are influenced by construals of the rejection experience that predict 3 distinct motives for prosocial, antisocial, and socially avoidant behavioral responses. The authors describe the relational, contextual, and dispositional factors that affect which motives determine people's reactions to a rejection experience and the ways in which these 3 motives may work at cross-purposes. The multimotive model accounts for the myriad ways in which responses to rejection unfold over time and offers a basis for the next generation of research on interpersonal rejection.
\end{abstract}

Keywords: interpersonal rejection, discrimination, belonging, motivation

Human beings are acutely responsive to how other people perceive, evaluate, and feel about them. Not only are people attuned to others' reactions to them, but perceiving that other people are interested, approving, or accepting typically evokes quite different reactions than perceiving that others are disinterested, disapproving, or rejecting (Leary, Koch, \& Hechenbleikner, 2001; K. D. Williams, 2001). Furthermore, positive and negative reactions from others often affect how people perceive and feel about themselves, their perceptions of other people, and the quality of their interpersonal relationships (Buckley, Winkel, \& Leary, 2004; Dion \& Earn, 1995; Downey \& Feldman, 1996; K. D. Williams, Cheung, \& Choi, 2000). And, over time, positive responses from other people foster psychological and physical wellbeing, whereas long-term exposure to negative interpersonal reactions is associated with psychological difficulties and poor physical health (Pressman \& Cohen, 2005; D. R. Williams, Neighbors, \& Jackson, 2003). In brief, other people's reactions exert a strong impact on people's thoughts, emotions, motives, and behavior, as well as their physical and psychological well-being. In this article, we provide a theoretical framework for understanding the complex reactions people have to rejection-related experiences.

In light of the pervasive and powerful effects of social evaluations, it is not surprising that social and behavioral scientists have started to devote attention to how people respond to positive and

Laura Smart Richman and Mark R. Leary, Department of Psychology and Neuroscience, Duke University.

This research was supported by a grant from the National Institute of Mental Health (1K01-MH-074942-02) to Laura Smart Richman. We are grateful to Kip Williams for his insightful comments on an earlier version of this article.

Correspondence concerning this article should be addressed to Laura Smart Richman, Department of Psychology and Neuroscience, P.O. Box 90085, Duke University, Durham, NC 27708. E-mail: 1richman@duke.edu negative reactions from other people and to the short- and longterm consequences of receiving approval and acceptance versus disapproval and rejection. Much of the earliest work along these lines involved children's reactions to being rejected by their peers, showing that peer rejection not only creates a great deal of suffering in the rejected child but also predicts negative emotional and behavioral outcomes in the future (Kupersmidt, Burchinal, \& Patterson, 1995; Prinstein \& Aikins, 2004). Similarly, rejection or abandonment by romantic partners has been studied in research on unrequited love, betrayal, and relationship dissolution (Baumeister, Wotman, \& Stillwell, 1993). Other work has examined the consequences of believing that one is a target of prejudice or discrimination because of one's race (Major, Spencer, Schmader, Wolfe, \& Crocker, 1998), weight (C. Miller, Rothblum, Felicio, \& Brand, 1995), or the possession of some other stigmatizing characteristic (Kleck \& Strenta, 1980). More recently, experimental studies have examined the effects of being rejected and ostracized by strangers on emotion, self-esteem, social judgments, and behavior (for reviews, see Abrams, Hogg, \& Marques, 2005; Baumeister \& Leary, 1995; Leary, 2001; K. D. Williams, 2001, 2007; K. D. Williams, Forgas, \& von Hippel, 2005).

Unfortunately, despite the amount of theory and research that has focused on the effects of negative interpersonal experiences, two difficulties have impeded a comprehensive understanding of these effects. First, this work is currently scattered across a number of disparate areas of behavioral science and appears under the guise of a variety of different phenomena such as ostracism, exclusion, rejection, discrimination, stigmatization, prejudice, betrayal, unrequited love, peer rejection, bullying, neglect, loneliness, homesickness, and humiliation. Even though these negative interpersonal experiences appear to have much in common, researchers interested in each of these topics rarely acknowledge the others, and efforts to integrate the findings across these areas have been meager. One of our goals in this article is to draw from and 
integrate these diverse literatures as we examine reactions to negative interpersonal events.

Second, the field lacks a broad framework for understanding the full range of consequences that occur when people experience negative interpersonal events. Although theorists have provided exceptional models and literature reviews that address reactions to specific kinds of experiences - such as peer rejection or ostracism (see, e.g., McDougall, Hymel, Vaillancourt, \& Mercer, 2001; K. D. Williams, 2001, 2007)—no one has yet incorporated all of the observed patterns, many of which appear inconsistent with one another, within a single overarching framework. For example, although most studies show that negative reactions from other people evoke emotions such as hurt, sadness, and anger (Leary \& Leder, in press; Vangelisti, Young, Carpenter-Theune, \& Alexander, 2005), some research finds emotional numbing instead (Twenge, Catanese, \& Baumeister, 2003). Likewise, people who are criticized, devalued, or ostracized are presumably motivated to repair their social images and restore others' good will, yet they often act in angry, aggressive, and antisocial ways that lead others to distance from them (Leary, Twenge, \& Quinlivan, 2006; Warburton, Williams, \& Cairns, 2006). Furthermore, people sometimes rebound quickly from episodes of rejection, whereas at other times the effects may linger for quite some time. And, as noted, although various types of negative interpersonal events share many common antecedents and effects, few efforts have been made to describe ways in which the effects of various types of experiences (e.g., discrimination, ostracism, peer rejection, loneliness) resemble versus differ from one another. Our goals are to offer an overarching model that explains the immediate and long-term effects of these experiences and to review the relevant literatures within that model, with a particular emphasis on explaining findings that may, on the surface, appear inconsistent with one another.

\section{Threatened Belonging as a Common Theme}

Negative reactions from other people take many formsdisinterest, criticism, prejudice, avoidance, rejection, betrayal, stigmatization, ostracism, neglect, abandonment, abuse, bullying, and a variety of minor slights and snubs. Thus, as a first step, we must consider what all of these categories of experiences have in common that may be responsible for their common effects on emotion, self-evaluations, and behavior.

We begin with the assumption that the psychological core of all instances in which people receive negative reactions from other people is that they represent, to varying degrees, threats to the goal of being valued and accepted by other people. In some instances, the threat to social acceptance is explicit, as when a child is ostracized by playmates, a group member is expelled from a group, or an employee is fired from a job. In other instances, the rejection is more implicit. For example, some manifestations of prejudice and stigmatization are couched in neutral (and even positive) terms (McConahay, 1986), instances in which people are avoided or ignored are often subtle, and people sometimes have difficulty knowing whether a criticism connotes well-meaning constructive feedback or a sign of social devaluation and lowered acceptance. In all cases, however, the potency of such experiences resides in the threat that they pose to people's sense that other people desire to accept and include them in interpersonal relationships and social groups. Thus, we begin with the assumption that, whatever other effects they might have, all negative interpersonal events have the potential to lower people's perceived relational value - the degree to which they believe that others value having relationships with them.

As will be seen, our model deals specifically with the cognitive, emotional, and behavioral effects of threats to relational value and, thus, to acceptance and belonging. In this way, it differs from K. D. Williams's $(2001,2007)$ model of ostracism, which includes the effects of rejection-related experiences not only on belonging but also on self-esteem, control, and meaningful existence. We agree with Williams that rejection-related experiences may produce a number of discrete threats-not only the four identified in his model but many others as well. In our view, however, these threats arise not from ostracism or rejection per se but rather from secondary features of a specific rejection episode. Indeed, these other threats may arise in situations in which ostracism is not involved and engage psychological processes that are distinct from those involved in reactions to threats specific to relational value. The secondary effects of rejection episodes (e.g., on one's sense of having a meaningful existence) certainly deserve research attention, but our focus in this article is on the core feature of all instances of rejection - the threat to relational value.

Baumeister and Leary (1995) reviewed a large body of evidence showing that human behavior, emotion, and thought are pervasively influenced by a fundamental interpersonal motive to obtain acceptance and to avoid rejection by other people-what they called the need to belong. This motive is thought to have an evolutionary origin, developing out of human beings' dependence on cooperative social relationships and group memberships for survival and reproduction throughout human evolution. A basic tenet of their theory is that achieving a sense of acceptance and belonging is necessary for psychological and physical well-being. Baumeister and Leary proposed that people who do not have their belonging needs satisfied, either because of a lack of opportunities to establish supportive relationships or because of rejection, will be in a state of deprivation that causes immediate effects on thought, emotion, and behavior and, if prolonged, a variety of long-term negative effects on health and adjustment.

\section{Immediate, Global Responses to Threatened Belonging}

Given the importance of interpersonal acceptance to people's well-being and the negative consequences of being inadequately accepted, it is not surprising that threats to acceptance and belonging are typically associated with negative affect. Although a few exceptions have been reported (to be discussed momentarily), the general pattern is for threatened belonging, whatever form it takes, to cause negative feelings such as hurt, sadness, anger, and general upset or distress (Leary, Koch, \& Hechenbleikner, 2001; Leary \& Leder, in press). Even when efforts are made to counterbalance the negative emotions that arise from rejection, by offering financial gain for being ostracized for example, participants still report strong negative feelings (Van Beest \& Williams, 2006).

Experimental studies that have studied emotional responses to rejection have led participants to feel rejected in a number of ways, including having them believe that other participants voted them out of a laboratory group, that another person did not wish to get to know them further after initially learning about or interacting with them, that another person preferred interacting with another 
participant rather than with them, that they were left out of a ball-tossing game (this has been conducted with actual ball-tossing as well as a computerized "Cyberball" game), and that they were selected last for a laboratory team. In the majority of these experiments, rejected participants reported significantly greater negative emotions than did accepted participants (Blackhart, Eckel, \& Tice, 2007; Bourgeois \& Leary, 2001; Buckley et al., 2004; Eisenberger, Lieberman, \& Williams, 2003; Leary, Cottrell, \& Phillips, 2001; Leary, Tambor, Terdal, \& Downs, 1995; K. D. Williams et al., 2000; Zadro, Williams, \& Richardson, 2005). Although less experimental research has been conducted on peer rejection in children, evidence suggests that the emotional effects are similar (Reijntjes, Stegge, Terwogt, Kamphuis, \& Telch, 2006).

Although a variety of negative emotions may occur when people are rejected (e.g., sadness, loneliness, hurt, anger, jealousy), the predominant rejection-related emotion appears to be "hurt feelings" (Leary \& Springer, 2000; MacDonald, in press; MacDonald \& Leary, 2005). Hurt feelings may, in fact, be the signature emotion that is associated with rejection, occurring from a person's appraisal that other people do not value their relationship with the individual as much as he or she would like, and, thus, rejection experiences typically involve at least some sense of feeling hurt (Leary \& Leder, in press). Although some theorists have suggested that hurt feelings reflect a blend of other emotions (such as sadness and fear; see Vangelisti, 2001; Vangelisti \& Young, 2000), research shows that participants' ratings of how "hurt" they feel reflect unique variance in affective experience that is not accounted for by the broad array of other emotions that are measured by scales such as the Multiple Affect Adjective Check ListRevised and the expanded form of the Positive and Negative Affect Schedule. Furthermore, hurt is distinctly predicted by appraisals involving low relational evaluation and the loss of relationships (Leary \& Leder, in press). In a cluster analysis of 135 emotion names, Shaver, Schwartz, Kirson, and O'Conner (1987) found that the item hurt was closely associated with items such as agony, suffering, and anguish, and a more comprehensive study of 525 emotion terms by Storm and Storm (1987) found that the item hurt clustered with items such as neglected, rejected, unwanted, unwelcome, betrayal, misunderstood, different, and isolated. Together, studies on the features of hurt feelings suggest that hurt is a distinct negative emotion that is associated with feeling devalued, unwanted, and rejected.

The effects of rejection on hurt feelings have been replicated with a number of paradigms and ways of inducing rejection, including leading participants to think that they were selected last for a team (Bourgeois \& Leary, 2001), providing bogus feedback indicating that another participant was not interested in what they had to say (Snapp \& Leary, 2001), giving participants feedback that other participants did not want to work with them (Buckley et al., 2004), and excluding participants from a ball-tossing game (Eisenberger et al., 2003). In these experiments, as well as in correlational studies, participants' ratings of how accepted or valued they felt correlated strongly with self-reported hurt feelings. Although most research on hurt feelings has involved adult participants, Mills, Nazar, and Farrell (2002) found that the events that children considered hurtful also tended to involve experiences in which they felt devalued, unimportant, or rejected. Importantly, people rate the pain associated with significant rejections, such as betrayal, as high as that associated with the pain experienced by cancer patients (Chen, Williams, Fitness, \& Newton, 2008). Other emotions often arise when people are rejected, particularly anger and sadness, but these emotions are probably not direct effects of rejection per se. Unlike hurt feelings, which appear to arise particularly from rejection or relational devaluation, these other emotions may be elicited by other features of the rejection episode (for data relevant to this hypothesis, see Leary \& Leder, in press).

Although most studies have found that rejection causes emotional changes, a few experiments have found that people sometimes experience "emotional numbness" instead (for a review, see Baumeister \& DeWall, 2005). Although there is little doubt that some studies have not found evidence that exclusion produces emotional distress, two points should be considered in interpreting these null findings. First, most of the studies that have not found effects of rejection-related manipulations on emotion have used a paradigm in which participants are told, on the basis of a measure that they completed earlier, that "you are the type who will end up alone later in life .... Relationships don't last, and, when you're past the age where people are constantly forming new relationships, you'll end up being alone more and more" (Twenge et al., 2003, p. 416). Unlike paradigms that commonly find emotional effects of rejection, this manipulation presumably does not induce a sense that one is currently being rejected. (In fact, the experimental manipulation explicitly acknowledges that "you may have friends and relationships now....") Thus, whatever its impact, the effects of the you-will-be-alone-later-in-life induction might not be expected to create precisely the same reactions as inductions that make people feel rejected in the current situation. Instead, it may induce concern, confusion, and consternation, which may be related to "numbness" and the deconstructed cognitive state described by Twenge et al. (2003). Emotional numbness responses may also reflect a way of disengaging in preparation for the possibility of future rejection. The difference between inductions that induce immediate rejection versus those that raise the specter of future rejection may parallel the difference between inflicting physical pain on a person versus telling the person that he or she is likely to develop a very painful ailment in the future. Actual pain may be accompanied by strong emotions, whereas telling people that they will experience pain later in life may lead to consternation and emotional numbness. Future research should examine differences in how people respond to immediate versus potential or predicted rejection.

A few other studies that used means of inducing rejection other than feedback that participants would be alone later in life have also found no effects on emotion, but null effects must always be interpreted cautiously because they can result from low power, inadequate measures, and other methodological problems as easily as from absence of an effect. We are not disputing the possibility that actual rejection may occasionally lead to emotional numbness, but the prevailing finding is that believing that one is rejected in the current situation, however rejection is induced, produces hurt feelings, often accompanied by sadness or anger. Indeed, a metaanalysis of more than 150 findings that involved the effects of laboratory-manipulated rejection on negative affect revealed a consistent effect (Blackhart, Knowles, \& Bieda, 2007).

The negative emotions that arise from perceived rejection are reliably accompanied by decreases in state self-esteem (for reviews, see Blackhart, Knowles, \& Bieda, 2007; Leary, 2006; Leary \& Baumeister, 2000). In laboratory experiments, manipulations 
that convey low relational value (e.g., rejection, disapproval, disinterest) consistently lower participants' state self-esteem (Leary, Cottrell, \& Phillips, 2001; Leary, Haupt, Strausser, \& Chokel, 1998; Leary et al., 1995; Nezlek, Kowalski, Leary, Blevins, \& Holgate, 1997; K. D. Williams et al., 2002; Zadro et al., 2005), and rejecting events in everyday life, such as unrequited love, are associated with negative self-feelings as well (Baumeister et al., 1993). Even imagining rejection can lower state self-esteem (Vandevelde \& Miyahara, 2005). Furthermore, the effects of performing certain actions on people's self-esteem closely mirror how they believe those behaviors will affect the degree to which others accept or reject them (Leary et al., 1995), and longitudinal research shows that perceived relational value prospectively predicts changes in self-esteem (Murray, Griffin, Rose, \& Bellavia, 2003; Srivastava \& Beer, 2005). Even people who claim to be unconcerned with other people's approval and acceptance show declines in self-esteem when they are rejected (Leary, Gallagher, et al., 2003).

The negative emotions (most notably hurt feelings) and lowered self-esteem that people experience in the wake of a rejectionrelated experience are the typical, global responses that occur immediately after rejection. The behaviors that accompany these immediate reactions differ considerably, however, and the theoretical model we propose attempts to explain the disparate behaviors that follow these initial responses. The degree to which these behaviors are instrumental in restoring belonging needs has important long-terms consequences for people's relationships as well as for outcomes involving their mental and physical health.

\section{A Multimotive Theory}

In the aftermath of a rejection experience, people nearly always experience three sets of motives more or less simultaneously, and these motives may promote competing behaviors. The first motive involves a heightened desire for social connections-in many cases with the person who has rejected them but often with other people who can provide acceptance and support. People may or may not always act on their urge to seek acceptance, but deficits in acceptance and belonging should always induce sociopetal motives. The second set of motives involves angry, antisocial urges to defend oneself or to hurt the source of the rejection. As we discuss in detail, people who are rejected often feel angry and sometimes act on their aggressive urges. Several writers have puzzled over why people who presumably wish to be accepted often behave in ways that drive away other people. Our model accounts for why people who feel rejected experience antisocial urges and describes factors that determine when aggressive reactions occur. Third, people who are rejected are also motivated to avoid further rejection and its accompanying hurt. As a result, they may withdraw from social contact, not only with those who have rejected them but sometimes from others whose acceptance they doubt. Obviously, social avoidance undermines people's efforts to gain acceptance, which raises provocative questions regarding why people sometimes avoid other people following interpersonal rejection. As we will show, recognizing that these three motives may arise simultaneously helps to explain certain inconsistencies in the literature and provides the basis for a more elaborated account of people's reactions to rejection.
Our theory proposes that which one of these motives predominates at a given time can be predicted by people's construals of the rejection event. Although there are nuances and complexities involved in each rejection experience, we propose that people make one or more of six possible construals involving the fairness of the rejection, expectations of relationship repair, pervasiveness or chronicity of the rejection, value of the damaged relationship, perceived costs of the rejection, and the possibility of relational alternatives. Our theory proposes that these six construals explain which of the three motives (seeking acceptance, harming others, and withdrawal) dominates people's responses after being rejected and predict long-term mental and physical health outcomes.

Our review of the literature is guided by our theoretical model shown in Figure 1. As described in greater detail as we proceed, events that connote rejection immediately elicit negative emotions and lowered self-esteem. As noted, the most common response to rejection involves the affective state colloquially called "hurt feelings," but anger, sadness, and anxiety may also occur. Then, people's construals of the rejection event determine the particular motive(s) that guide behavioral responses. Although a given construal does not definitively determine a particular motive, we suggest that particular patterns of construal make certain responses more likely. For example, when the rejection is perceived as unfair, then antisocial responses will be more likely. When expectations of repairing the relationship are high, the relationship is highly valued, and the costs of losing the relationship are high, then people will likely be motivated to behave in prosocial ways that promote acceptance with the rejector and use tactics that restore a sense of belonging. In contrast, withdrawal motivations are generated from the beliefs that viable alternative relationships are available and that the rejection is chronic and pervasive. Over time, each of these responses will either restore the person's relational value and acceptance or fail to do so, with consequences for whether the person experiences positive or negative outcomes with respect to psychological and physical well-being.

\section{Rejection/Relationship Construals: Predictors of Relationship-Promoting, Antisocial, and Avoidant Motivations Following Rejection}

People who feel rejected manifest competing motives to regain relational value, verbally or physically aggress against the rejector, and/or withdraw from further social interaction. Given the complexity of rejection episodes and the benefits and costs associated with various courses of action, the fact that people experience these three competing motives is not surprising. A person who has been rejected may simultaneously wish to regain acceptance, retaliate against those who hurt him or her, and avoid further social contact. In this section we address the question of why people's reactions in the wake of rejection may take one path versus another by describing the construals that people make.

\section{Perception of Unfairness or Injustice}

In the eyes of the person who has been rejected, the rejection may be deserved and fair or undeserved and unfair. In some instances, people recognize that others have devalued or rejected them for good reason. In such cases, people should feel sad, remorseful, or self-pitying and want to reestablish their relational 


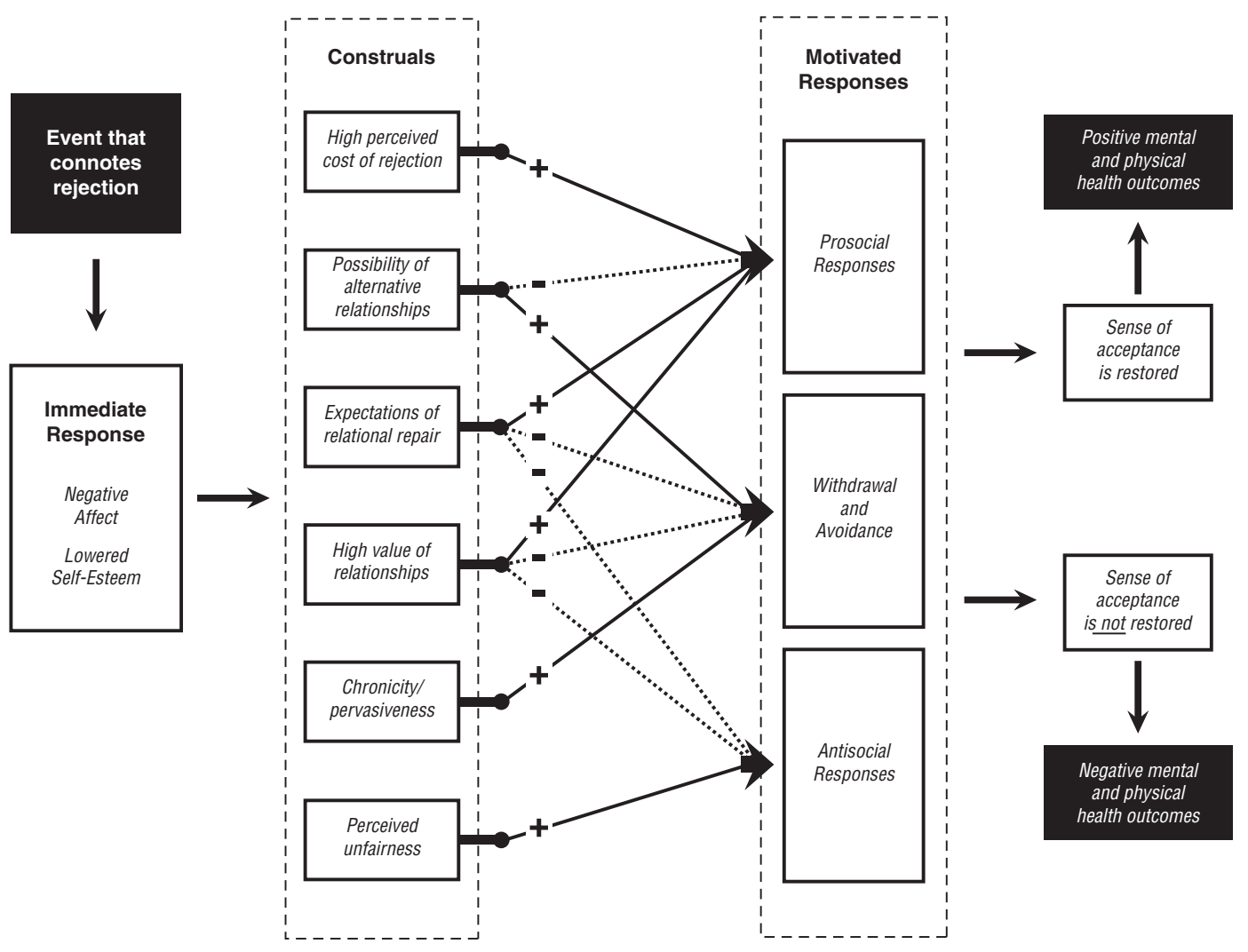

Figure 1. Multimotive model of reactions to interpersonal rejection experiences.

value, but they are not likely to become angry with those who devalued them (although they might be angry at themselves). A team member who perceives that she has been justly benched by the coach and marginalized by other players for atrocious performance on the field, a person who knows that he has alienated a friendship through betrayal, and a person who has been justly criticized for behaving badly are likely to feel sad or guilty and to try to make amends.

In contrast, rejections that seem unfair or unjustified tend to lead to anger and antisocial actions. Research shows that people react angrily when they are treated unfairly or disrespectfully (Lind \& Tyler, 1988). Even when nothing tangible is at stake, being treated unfairly may signal that people's status or image has been compromised, and they may assert themselves to reestablish it (D. T. Miller, 2001). Indeed, Solomon (1990) suggested that anger is inherently associated with the perception of injustice. Thus, when people perceive that they were rejected for trivial, unwarranted, or unfair reasons, they are more likely to feel angry and behave antisocially. Episodes of rejection that are based on group memberships such as race, ethnicity, nationality, religion, or sex may appear particularly unjust to the rejectee, which may help to explain the angry reactions that are observed in response to prejudice and discrimination. These perceptions of injustice are at times so powerful and widespread within an oppressed group that they give rise to social movements such as the civil rights movement, women's liberation, or other collective action on behalf of marginalized groups.

\section{Expectations of Relational Repair}

When a rejection episode occurs, the rejected individual likely holds some subjective probability of regaining relational value vis-à-vis the fractured relationship. Our model predicts that prosocial responses will predominate when people perceive that the relationship can be repaired. When the likelihood of regaining relational value is reasonably high, people should not only try to reestablish the relationship but will also not wish to undermine their standing further and, thus, should behave prosocially. Alternatively, the probability of antisocial and avoidant reactions increases with decreasing perceived probability of relational rapprochement. Put simply, people who believe that a social bond is irrevocably broken may have few reasons to restrain their animosity, to behave positively, or to interact with the rejector.

\section{Value of the Relationship}

The motivation to respond in ways intended to restore a relationship once a rejection episode has occurred is in part determined by the degree to which the relationship is valued by the rejectee When people are rejected in the context of a relationship that they highly value, they should be strongly motivated to repair it. Repair efforts often take the form of prosocial behaviors that create goodwill and win favor in the eyes of the rejector. Caring about whether the relationship with a romantic partner, friend, colleague, or social group persists is one factor that drives prosocial strategies 
to respond to the rejection. In contrast, when a relationship is not highly valued and an act of rejection occurs, other motivational responses of aggressing or withdrawing may dominate. These responses are particularly likely in less established relationships or in reaction to brief, isolated acts of stigmatization or ostracism both because the relationship is regarded as less valuable and because the person has less investment in it.

\section{Possibility of Alternatives}

The sting of rejection can be soothed if people perceive (or even imagine) the possibility of relationship alternatives. When the perceived possibility of relational alternatives is high, withdrawal motivations will dominate. In these cases, people are less motivated to behave prosocially to repair the relationship in which the rejection occurred and are not motivated by antisocial urges to lash out in anger. Rather, the possibility of other friendships, romantic relationships, work options, or social groups motivates a response to disengage from the current relationship in order to pursue others.

Baumeister and Leary (1995) suggested that the belonging motive is characterized by substitutability in the sense that new relationships and memberships can psychologically replace those that have ended. When this happens, the person's reaction to the rejection-whether it is initially prosocial, antisocial, or avoidant-diminishes in intensity. The previous relationship becomes less important, and the rejection is less salient as new relationships emerge. Of course, even after they develop new relationships or join new groups, people sometimes harbor hurt, sadness, or anger about the earlier rejection for some time afterwards, but the possibility of relational alternatives typically attenuates their response. Much like Thibault and Kelley's (1959) conceptualization of comparison-level-for-alternatives, if people expect that they may receive more rewards (greater satisfaction of acceptance needs) in an alternative relationship, they may reduce their commitment in the current relationship and engage in more withdrawal/avoidant responses. However, if people do not perceive that desirable alternatives are available, they will likely maintain their investment in their relationship and engage in more prosocial behaviors.

\section{Chronicity and Pervasiveness}

Some rejections are one-time affairs and, even when there is no possibility of relational rapprochement, people can usually put the episode behind them. In other cases, however, rejection occurs in an ongoing and persistent series of specific events, sometimes over a prolonged period of time. The chronic target of childhood bullying, the person who receives the cold shoulder from a family member over many years, and the immigrant who confronts pervasive negative community attitudes in the new country may experience a pattern of chronic rejection that may in extreme cases last a lifetime. Our model predicts that perceptions of a pervasive, chronic nature to the rejection will predict withdrawal and avoidant patterns of responses.

Often, targets of pervasive and chronic rejection show evidence of resorting to behaviors that undermine physical health. For example, people who show ongoing experiences of discrimination show higher rates of smoking (Landrine \& Klonoff, 1996), drug use (Gibbons, Gerrard, Cleveland, Wills, \& Brody, 2004), and alcohol use. Internalized racism (beliefs in the inferiority of African Americans that likely stem from repeated exposure to racial discrimination) is also associated with higher alcohol use (Borrell et al., 2007). At present, it is unclear whether these reactions to chronic rejection reflect efforts to be accepted by subgroups who use alcohol and drugs, failures of self-regulation that can arise from persistent rejection (Baumeister, DeWall, Ciarocco, \& Twenge, 2005), or self-medicating efforts to reduce distress as people withdraw from social interaction (see also Pascoe \& Smart Richman, 2008). Further research is needed on the negative effects of chronic rejection on health-related behavior.

\section{Perceived Costs of the Rejection}

When people perceive that rejection carries many costs, their motivation should be high to behave prosocially and repair the relationship. For example, people who have been rejected by a romantic partner or friend may imagine a future filled with loneliness and despair, and people who have been ostracized by a particular group may face ongoing embarrassment and humiliation, high costs that motivate them to repair the damaged relationships. Furthermore, the more that people have invested in a relationship - in terms of time, effort, money, shared experiences, and social identity - the more costly a rejection will seem, and the more motivated they will be to restore it (Rusbult, 1980). The chance for future rejection may also be a cost associated with a rejection episode as when the loss of one friendship can lead to an exclusion from an entire social circle. In these cases, people should be motivated to engage in prosocial strategies to reduce the chances of these negative outcomes occurring.

\section{Relationship-Promoting Responses}

According to our model, each rejection construal increases the likelihood of one of the three categories of responses. We begin in this section by examining in detail the prosocial reactions to rejection that appear designed to increase one's acceptance in the eyes of other people and to promote one's relationships with them, then turn to aggressive and antisocial responses in the subsequent section, followed by a discussion of instances in which people withdraw from and avoid interaction.

\section{Cognitive Processing}

First, experiences of rejection promote cognitive processing related to belonging. Pickett and Gardner (2005) described a model for the regulation of belonging by which people monitor social information that may provide cues to belonging and inclusion. Although people probably monitor their relational value on an ongoing basis, they become particularly sensitive to rejection cues when they feel inadequately accepted. As a result, being rejected makes people more sensitive to cues that reflect on their relational value. For example, compared to people who have been accepted, those who are rejected are more sensitive to the emotional tone of other people's voices and more accurate in detecting emotions from others' facial expressions (Pickett, Gardner, \& Knowles, 2004). These findings suggest that rejection heightens people's attention to social information, possibly in an effort to understand 
others' reactions or to obtain information that might help to repair a damaged relationship or forestall future rejection.

Similarly, threats to belonging affect the retention of social information. Gardner, Pickett, and Brewer (2000) had participants engage in an Internet chat session in which they were either accepted or rejected. They then read about 4 days in the life of an undergraduate student in the form of diary entries. The entries contained social information related to the student's relationships as well as nonsocial information about the individual's behavior. Participants then completed an unexpected memory task involving the hypothetical student's diary entries. They found that after a rejection experience, participants recalled a smaller proportion of the student's nonsocial, individual activities and a larger proportion of the social activities. When belonging is threatened, people appear to be more attuned to information that is relevant to their social relationships and are better at remembering this information.

\section{Promoting Relational Value}

Rejection often leads people to behave in ways that should enhance acceptance by other people. For example, women who were ostracized from a ball-toss game worked harder on a subsequent group task, presumably because groups are more likely to accept hard workers (K. D. Williams \& Sommer, 1997). Similarly, rejected individuals display enhanced cooperation in a social dilemma (Ouwerkerk, Kerr, Gallucci, \& Van Lange, 2005) and conform more to the opinions of other people (K. D. Williams et al., 2000), both of which may prompt greater acceptance. Furthermore, people who score high in the need to belong are more likely to cooperate in group settings than those who score low (DeCremer \& Leonardelli, 2003), supporting the notion that people may cooperate to facilitate acceptance.

In a series of studies that used a variety of methods to induce a sense of social exclusion, Maner, DeWall, Baumeister, and Schaller (2007) found that exclusion was related to increased affiliation. Compared to other conditions, excluded participants wanted to make new friends, desired to work with others on a laboratory task, rated potential interaction partners more positively, and allocated larger cash rewards to other participants (but only when they expected to interact with them later). Importantly, these affiliative behaviors were directed primarily toward those who did not perpetrate the rejection and who offered the potential for future relationships. In contrast, participants tended to treat those who rejected them with contempt and did not allocate rewards to them when given the opportunity. Similarly, Shelton, Richeson, and Salvatore (2004) found that when ethnic minorities were primed to expect racial prejudice, they were more socially engaged during the interaction than control participants even though they liked their partner less, experienced more negative affect, and felt less authentic compared to participants who were not primed with such expectations. 101Shelton et al. also found that the more ethnic minorities had a dispositional tendency to expect prejudice, the more they disclosed information about themselves to their White roommate, possibly reflecting strategies that people employ to foster positive relationships when the potential for prejudice and rejection is high.

\section{Automatic Behaviors}

Some of the socially facilitative behaviors that occur when people are concerned with social acceptance appear to be automatic and nonconscious, as in the case of behavioral mimicry and social tuning. Relationships in which people feel strong emotional bonds tend to be marked by nonconscious behavioral mimicrythe tendency to imitate the behavior of others without awareness. Furthermore, when an experimental confederate mimics participants' nonverbal behavior, they report greater liking for the confederate and rate the interaction with him or her more positively (Chartrand \& Bargh, 1999), showing that behavioral mimicry increases liking.

Behavioral mimicry also appears to increase after rejection. Compared to those who were included, participants who were excluded from a Cyberball game tended to mimic their interaction partner (actually a confederate) in a subsequent task by more closely matching the amount of foot-shaking that she did (Lakin \& Chartrand, 2003). Furthermore, this nonconscious mimicry led the confederate to rate interactions with the excluded foot-shakers more positively than interactions with participants who had been included.

Along the same lines, research on affiliative social tuning has identified nonconscious strategies that people use to maintain social connections. According to shared reality theory (Hardin \& Conley, 2001), social bonds are established and maintained to the degree that people believe that others share their social beliefs. In affiliative social tuning, the motive to get along with another person is related to attitude shifts in the direction of the other person's attitudes. In one study, Sinclair, Lowery, Hardin, and Colangelo (2005) found that participants expressed views that corresponded more closely to the ostensible views of their interaction partner when their affiliation motivation was high. This effect was obtained even among African Americans who thought they were going to interact with someone who held stereotypical views of African Americans - an interaction with a high risk for rejection. These findings suggest that the motivation to avoid rejection may automatically lead to cognitive changes that facilitate acceptance.

\section{Alternative Sources of Support}

When efforts to restore a damaged relationship are unsuccessful, prosocial strategies to restore relationships can be directed to alternative relationships and sources of support. Given that people need a minimum number of strong, supportive relationships (Baumeister \& Leary, 1995), people who are unable to reestablish satisfying connections with those who have rejected them are motivated to seek alternative relationships. This effect can be seen in research on repartnering following divorce, which showed that $50 \%$ of the respondents started dating even prior to filing for divorce and that by 1 year after filing for divorce people had typically dated two new partners (E. R. Anderson et al., 2004). Likewise, being turned down for membership by one group may be quite hurtful, but people generally seek alternative groups that erase the pain and fulfill their need to belong. Because of substitutability, when people are unable to reestablish a relationship that has been damaged or destroyed by rejection, they usually seek acceptance and belonging from other people, and they tend to do so rather quickly. 
In addition to searching for new sources of acceptance, people who have been rejected may seek social support from those with whom they already have connections. As noted, rejection can be conceptualized as a type of stressful event, and extensive research has shown that social support buffers people against stress and fulfills emotional, informational, and logistical needs (Cohen \& Wills, 1985; Holahan \& Moos, 1985; Taylor, 2007). Turning to one's social support network after rejection may be particularly beneficial because, in addition to its other functions, social support provides reminders that one has important, supportive relationships and, thus, helps to restore a sense of belonging.

Along these lines, Noh and Kasper (2003) found that seeking social support in response to racial discrimination was associated with lower levels of depression, and Clark (2006) found that the tendency to seek social support in response to racism moderated the relationship between past experiences of perceived racism and blood pressure reactivity during a stressor task. Specifically, perceived racism was positively associated with reactivity only among people who did not tend to seek social support. Similarly, Smart Richman, Pek, Malone, Siegler, and Williams (2008) found that perceived social support buffered the effects of discrimination experiences by protecting people from depression. Although this study did not ask participants whether they sought social support as a direct response to discrimination experiences, perceiving that social support was available clearly buffered people against the stress associated with interpersonal devaluation and protected them against depression.

Joining support groups may be another way that people restore belonging after a particular experience of rejection or deal with ongoing devaluation because of stigmatizing conditions that present chronic challenges to being accepted. Thousands of support groups exist for people who have experienced rejection (e.g., groups for people who are out of work or divorced) or who have stigmatized identities involving, for example, nonconventional sexual practices, problems with alcohol and drug use, and stigmatized medical conditions such as cancer and psoriasis. For example, cancer patients join support groups not only to obtain information about cancer and its treatment but also because such groups provide a sense of community and acceptance that counteract the isolation and rejection that cancer patients frequently experience (Taylor, Falke, Shoptaw, \& Lichtman, 1986; Ussher, Kirsten, Butow, \& Sandoval, 2006). The broad appeal of support groups is based largely on the maintenance of interpersonal contact among people who otherwise feel devalued and isolated. Such contact is achieved in various ways, ranging from face-to-face group meetings to chat rooms and other online forums that promote the idea that "you are not alone." Support groups may also provide information and companionship through newsletters, telephone chains, listservs, Internet forums, and mailing lists, providing ongoing reminders of belonging even if the group is not meeting face-toface.

Group identification. Another way in which people regain a sense of connectedness with others involves strengthening their group identity. Schmitt and Branscombe (2002) described processes by which group identification protects the well-being of disadvantaged (and chronically rejected) groups. They suggested that perceiving prejudice increases group-based identification which, in turn, enhances well-being. This effect may occur via two routes. First, as people identify more strongly with their group, they may become more engaged with the group, thereby affording them opportunities for social support from group members. In addition, for members of disadvantaged groups, having a strong group identity might counter the psychological sense of feeling devalued by the dominant culture by providing members with a sense of belonging and acceptance. When people are highly identified with their group, they feel a stronger sense of belonging and have greater access to people to whom they feel a social connection and on whom they can depend. In this way, group identity may reduce the impact of rejection on well-being. Along these lines, Schmitt and Branscombe suggested that when members of disadvantaged groups perceive that acceptance by powerful groups is unlikely, increasing psychological investment in one's ingroup may be the best strategy for feeling accepted and maintaining psychological well-being.

Having a strong racial identity may also buffer the adverse effects of acute and chronic discrimination on mental and physical health (D. R. Williams, Spencer, \& Jackson, 1999). Overall, the more that African Americans and women perceive discrimination based on their racial or gender group membership, the poorer psychological adjustment they exhibit. However, intergroup identification has been found to moderate the relationship between rejection and well-being among ethnic minorities. Sellers and Shelton (2003), for example, found that aspects of racial identity were related to lower psychological distress in response to perceived racial discrimination.

\section{Cognitive and Symbolic Tactics for Restoring Belonging}

As we have seen, people who feel rejected are typically motivated to regain acceptance, either from the rejector(s) or from other people. However, people are sometimes unable to obtain the acceptance that they desire, and some individuals live for extended periods with a chronic deficit in belonging. Under such circumstances, people may engage in cognitive and symbolic tactics that increase their sense of acceptance and belonging even though they are not actually accepted as much as they wish. Whether these tactics are effective in counteracting the long-term psychological and physical effects of rejection is unclear, but they probably reduce the negative emotions that are associated with feeling rejected.

First, research has documented several instances in which people interpret situations in a biased manner that helps to satisfy their desires or reduce negative emotions. For example, in the interpersonal domain, people sometimes interpret the actions of those who are close to them, such as romantic partners, in ways that assure them of the other person's love and support, and they may be particularly prone to do so when their worth as a relational partner is called into question (Murray \& Holmes, 2000; Murray, Holmes, \& Griffin, 2000). Presumably, bolstering one's perceived relational value in this way quells unsettling doubts about one's social desirability and the viability of the relationship. Similarly, Carvallo and Pelham (2006) found that people are more willing to acknowledge that they have experienced discrimination after being led to feel accepted, possibly because acknowledging devaluation is less threatening when one feels accepted. Clearly, rejection does not always lead to this sort of compensatory effect, and in fact, people sometimes react to rejection by one person by feeling that they are less acceptable to everyone. More research is needed to 
identify the conditions under which signs of rejection lead people to boost their confidence in their relationships versus generalize their unacceptability.

A second, cognitive route to increasing one's sense of acceptance, or at least of one's acceptability, may be provided via self-affirmation (Sherman \& Cohen, 2006; Steele, 1998). Research suggests that people may counteract some of the negative effects of rejection by affirming important aspects of themselves that are not implicated in the rejection. However, we suggest that the route by which self-affirmation effects occur may be different than many have assumed. Viewed from the perspective of acceptance and belonging, self-affirmation may remind people of their valued attributes-characteristics that would make them valued, sought after, and accepted by other people (see Leary, 2007). Thus, self-affirmations should work best when they highlight attributes that incontrovertibly connote acceptance by other people and remind people of their interpersonal connections. Along these lines, when participants were led to think of valued personal attributes in a way that implied that their acceptance by others was tenuous and contingent on good performance, beneficial effects of selfaffirmation were not obtained (Schimel, Arndt, Banko, \& Cook, 2004).

Third, tangible, symbolic reminders of one's social connections can also help to restore a sense of belonging, at least temporarily. Gardner, Pickett, Jefferis, and Knowles (2005) proposed that, just as people who are hungry but do not have the opportunity to eat a meal may snack on food, people who feel inadequately connected but do not have access to actual accepting relationships may "snack" on symbolic reminders of their social connections. Social snacking may take the form of looking at photographs of or rereading e-mail messages or letters from family, friends, and romantic partners or even just daydreaming about them. Presumably, people are more likely to engage in social snacking when they feel rejected or are experiencing a deficit in belonging because those who accept them are not present. Consistent with this hypothesis, social snacking was more likely among people who scored high on a trait measure of the need to belong (Gardner, Jefferis, \& Knowles, in press) and among students who had been led to imagine studying alone all day. Similarly, the typical effects of rejection on aggression were eliminated when people who were not chosen for a group task wrote about their best friend (Twenge, Baumeister, DeWall, Ciarocco, \& Bartels, 2007).

Likewise, as Gardner et al. (2005) noted, parasocial relationships-attachments to movie stars, television personalities, musicians, sports figures, and other celebrities-may provide comfort and a sense of social connection even though the "relationship" is distal and nonreciprocated. Koenig and Lessan (1985) found that viewers regarded their favorite television performers as closer than an acquaintance but not as close as a friend, and Perse and Rubin (1989) noted that people may use the same cognitive processes when thinking about parasocial relationships as they do real relationships. In general, researchers have assumed that people maintain parasocial relationships to fill unmet social needs and reduce loneliness (Koenig \& Lessan, 1985; Rubin, Perse, \& Powell, 1985), but little is known regarding how people use parasocial relationships following rejection. We predict that people who feel rejected and devalued may be more likely to watch television shows and movies that include performers to whom they feel parasocially close. For the same reasons, we also expect that people might even develop stronger attachments to nonhuman animals after rejection, a hypothesis that is supported by the fact that people whose feelings of social isolation were increased experimentally showed a greater tendency to anthropomorphize (Epley, Waytz, \& Cacioppo, 2007).

\section{Summary}

Our model predicts that people who have been devalued or rejected but who have high expectations for relationship repair, who value the damaged relationship highly, or who perceive that there are many costs associated with a loss of the relationship show evidence of being motivated to repair the damaged relationship and/or seek acceptance from other people who were not involved in the rejection. Rejection leads people to attend more closely to interpersonal cues and behave in ways that promote their relational value (e.g., by being helpful or cooperative) and even elicits automatic, nonconscious actions that increase others' liking for them. Seeking alternative sources of acceptance may occur after initial attempts to restore the damaged relationship are unsuccessful and may be particularly adaptive in long-term adjustment to rejection when the opportunity does not exist to repair that specific relationship. These alternative strategies may also occur in conjunction with relationship-promoting efforts. Furthermore, when people have temporary feelings of loneliness or chronic deficits in belonging, they may think about themselves and their social lives in ways that attenuate the distress associated with these deficits of interpersonal connections. These cognitions do not stem from rejection episodes per se, but do serve to ease, at least temporarily, the feelings associated with not having access to meaningful relationships. Given that belonging appears to be a fundamental need, we should not be surprised that deficits in acceptance instigate a motive to improve one's relational value.

\section{Antisocial Responses}

Several writers have observed that people's behavioral responses to perceived rejection are often counterproductive to regaining acceptance and belonging and, in fact, sometimes reduce the person's chances of future acceptance. We propose that these responses are most likely to occur when the rejection is construed to be unfair and the relationship is not valued. Three particular sets of antisocial reactions to rejection have been studied-anger and aggression, lowered empathy, and impaired self-regulation.

\section{Anger and Aggression}

Anger and aggression are common responses to rejection episodes, despite the fact that they often lead to long-lasting, if not permanent, breaks in social bonds. In a review of the link between rejection and aggression, Leary et al. (2006) found strong, consistent relationships between rejection and anger/aggression. A variety of laboratory manipulations of rejection have produced increases in aggression as measured by participants' willingness to blast an opponent with white noise (Twenge, Baumeister, Tice, \& Stucke, 2001), have another person listen to aversive audiotapes (Buckley et al., 2004), or require a person who did not like spicy food to eat hot sauce (Warburton et al., 2006). Interestingly, Warburton et al. (2006) found that participants who were able to 
restore control after rejection did not show aggressive responses, suggesting that loss of control may play a role in evoking antisocial behaviors when one is rejected. Furthermore, people's reports of feeling rejected or excluded predicted aggressive behavior in both laboratory experiments and field studies (see Leary et al., 2006, for a review). In addition, certain instances of real-world violence appear to be precipitated by feelings of rejection, such as when estranged husbands kill their wives (Barnard, Vera, Vera, \& Newman, 1982; Crawford \& Gartner, 1992), ostracized students shoot their classmates (Leary, Kowalski, Smith, \& Phillips, 2003), men rape women who refuse their advances, and gang members attack those who have "dissed" them (i.e., treated them disrespectfully). The Columbine shootings in 1999 and the Virginia Tech massacre in 2007 are tragic examples in which the shooters had a history of being teased, bullied, and ostracized. Of course, most people do not resort to lethal violence when they are rejected, but anger and aggressive urges are commonly observed in response to feeling devalued even if those urges do not result in overtly aggressive actions. (See Leary, Kowalski, et al., 2003, for a discussion of other factors that may be needed to turn rejection into homicide.)

Several decades of research have also found relationships between peer rejection and aggression among children (for reviews, see Asher \& Coie, 1990; Asher, Rose, \& Gabriel, 2001; McDougall, Hymel, Vaillancourt, \& Mercer, 2001). Much of this research has been correlational, leading to ambiguity regarding the direction of the relationship. Evidence for both directions exists—aggressive children are certainly more likely to be rejected, and, more relevant to our concerns here, rejection causes aggression. In one longitudinal study, Kupersmidt et al. (1995) found that rejection prospectively predicted aggression in elementary and middle school students, and as rejection increased over time, so did aggression.

People who have the tendency to be highly sensitive to being rejected are particularly likely to have antisocial reactions to rejection (Downey, Freitas, Michaelis, \& Khouri, 1998). In a study of conflicts in dating relationships, high (compared to low) rejection-sensitive women engaged in more negative behaviors such as using a hostile or negative tone of voice, demeaning or mocking their partner, and using gestures that convey disapproval or disgust. Not surprisingly, such responses tended to lead their partners to distance themselves, which presumably fueled further antisocial reactions from the women. Importantly, women who were high in rejection sensitivity reacted with greater hostility than women low in rejection sensitivity only when the situation involved feeling rejected, demonstrating that the effect is specific to rejection and not to negative events in general (Ayduk, Downey, Testa, \& Yen, 1999). Although Downey et al. (1998) did not find this pattern in men, they did find that men who were both high in rejection sensitivity and very invested in their romantic relationships were more likely to behave violently toward their dating partners than men who were low in rejection sensitivity or men who were high in rejection sensitivity but less invested in their relationships.

The pressing question is why people who are rejected sometimes aggress against those who rejected them and, in some cases, against those who may have had nothing to do with the rejection. If we assume that people are motivated to be accepted, then we might expect that people who are rejected would quickly try to thwart the rejection through positive, prosocial actions that endear them to other people. Yet, the evidence shows clearly that people are willing to sacrifice others' acceptance and goodwill by expressing anger and behaving aggressively.

After their extensive review of the relevant literature, Leary et al. (2006) were unable to draw a firm conclusion regarding the cause of rejection-elicited aggression. Instead, they suggested that the effect is multiply determined and offered several plausible hypotheses that could account for the phenomenon: (a) Rejection is a source of pain, and pain can elicit spontaneous aggression; (b) because rejection blocks people's goals, it creates frustration that leads to aggression; (c) rejection threatens self-esteem, and such threats might cause aggression; (d) people who are rejected believe that aggressing will improve their mood; (e) people aggress as a social influence tactic to coerce others not to abandon them; (f) aggression helps people to reestablish control in difficult social encounters; ( $\mathrm{g}$ ) people aggress out of retribution purely to punish those who have hurt them; (h) the dissolution of a social bond lowers restraints against antisocial reactions, leading to disinhibited behavior; and (i) rejection interferes with self-regulation, leading people to lose control. We add to this list the possibility that rejection-elicited aggression may reflect a case of displaced aggression in which the perpetrator has been frustrated by a previous, unrelated event and a subsequent rejection experience serves as the trigger for aggressive actions. Pederson, Gonzales, and Miller (2000) demonstrated that relational violence can be precipitated by a trivial relational exchange if one partner has previously experienced an aversive, anger-inducing event.

Space does not permit us to examine in depth the question of why people who are rejected seem willing to risk further rejection by behaving aggressively, but our multimotive model may shine a bit of light on it. In most instances in which other people pose a threat to our well-being, anger and aggression are potentially beneficial responses. When we are being robbed, lied to, or physically attacked, for example, anger and aggression help to stop the malevolent action and possibly deter future incidents. However, when our well-being is being threatened by interpersonal rejection, the same anger and aggression that might thwart other kinds of threats usually fail to assist us in avoiding rejection and, in fact, often make matters worse. Even so, because we naturally respond aggressively to unjustified threats to our well-being (Solomon, 1990), the heightened desire for acceptance is accompanied by anger and the urge to harm.

Furthermore, aggression and other antisocial reactions may arise from different processes immediately after rejection than they do later. Immediately after being rejected, anger and aggression may occur as a result of the pain or frustration associated with being rejected, the effects of displaced aggression arising from a previous event, the result of behavioral dysregulation, or an impulsive effort to influence the rejector to reconsider. People may well be motivated to be accepted, but their immediate antisocial reactions may reflect spontaneous reactions borne of hurt, frustration, anger, or dysregulation, or mismanaged efforts to forestall the rejection.

Aggression that occurs later-after the initial rejection episode-is more likely to be motivated by revenge, as when the spurned lover returns to slash the ex-partner's tires or the ostracized student opens fire on his classmates. At this point, the person has given up trying to be accepted and harbors intense animosity toward the rejector or sometimes more broadly toward anyone who is perceived as sharing common characteristics with the rejector. 
Thus, the person is motivated by revenge or retribution, believes that justice requires a strong response, and may see few, if any costs to aggressing. (For a review of research on reactive vs. proactive aggression, see Bettencourt, Tally, Benjamin, \& Valentine, 2006.)

\section{Lowered Empathy and Prosocial Behavior}

In some cases, being excluded is related to lower empathy, which may increase the likelihood of antisocial responses. For example, DeWall and Baumeister (2006) found that the you-willbe-alone-later-in-life manipulation caused participants to have less empathy for someone who supposedly experienced a romantic breakup and that exclusion induced by recalling an experience of rejection led to lower empathy for someone who had a broken leg. Similarly, Twenge et al. (2007) found that the future-alone manipulation caused a reduction in prosocial behavior, as reflected in donating less money to a study fund, not helping a researcher pick up pencils that he or she dropped, and cooperating less during a prisoner's dilemma game. Importantly, they also found that a reduction in empathic concern mediated the drop in prosocial behavior following the future-alone induction. In other studies, rejection predicted a lower likelihood of helping an experimenter and volunteering for future experiments (Twenge et al., 2007) and being less likely to assign another participant to listen to pleasant, as opposed to neutral or aversive, sounds (Buckley et al., 2004). In the Buckley et al. (2004) study, rejected participations also indicated that they were less inclined to behave nicely toward the person who rejected them, for example by smiling at or paying attention to him or her. Overall, research suggests that rejection is related to relationship-damaging responses such as lower empathy and less pleasant behaviors, but primarily in cases when people do not perceive an opportunity for relationship repair.

\section{Impaired Self-Regulation}

Rejection may also lead to difficulties in self-regulation that, although not antisocial in themselves, might undermine people's efforts to obtain acceptance, make it more difficult for them to restrain aggressive urges that arise, or have other undesired effects. Studies show that rejection may lower people's motivation to make themselves respond in the most beneficial way when doing so requires them to delay gratification and resist their immediate impulses. For example, Twenge, Catanese, and Baumeister (2002) found that the future-alone manipulation caused people to make poorer choices that lowered their chances of winning money, choose less healthy snacks, obtain less useful information about their health, and exercise less when given the opportunity. Participants were also more likely to procrastinate after imagining being alone later in life compared to imagining future belonging or misfortune. Likewise, Twenge et al. (2003, Experiment 1) found that, compared with accepted participants, people who believed that they had been rejected were less likely to delay gratification in choosing hypothetical jobs, opting for the immediate rewards of a high-paying job with little opportunity for advancement or better income over a job with a lower starting salary but more opportunity for advancement and higher future income. Along the same lines, Baumeister et al. (2005) found that participants who were told that they would end up alone later in life had greater difficulty making themselves consume a healthy but bad-tasting beverage and persist at a frustrating task. Most of the studies that have examined the effects of rejection on self-regulation used the future-alone paradigm, which, as discussed earlier, does not induce a sense of being rejected in the current situation and may elicit other effects. Even so, when rejection was manipulated directly using exclusion by other participants on a group task, participants also showed evidence of impaired selfregulation (Twenge et al., 2003).

Some of these impairments in self-regulation may arise from the effects of rejection experiences on cognitive functioning. For example, Baumeister, Twenge, and Nuss (2002) found that participants who were told that they would end up alone in life had greater difficulty controlling their attention in a dichotic listening task. Similarly, Inzlicht, McKay, and Aronson (2006) found that when stigmatized groups-African Americans in one study, and female students in another-were made aware of their stigmatized status through a stereotype threat manipulation (in which they thought they were taking a test that was diagnostic of intellectual or math ability), self-regulation was compromised. In these studies, the saliency of one's stigmatized status was related to deficits in attentional focus as evidenced by slower reaction times on a Stroop interference task, as well as less physical self-regulation as measured by persistence on a handgrip task. Reflecting on having a future alone also resulted in lower scores on IQ and Graduate Record Examination test items and poorer performance on complex cognitive tasks involving effortful logic and reasoning, both of which may occur when people do not devote sufficient attention to the task at hand (Baumeister et al., 2002). Ruminating about real or imagined rejection may usurp the cognitive resources needed to consciously regulate one's attention and behavior.

Similar performance decrements have also been found in response to stereotype threat, where performance on a task is compromised when a stereotype or stigmatized social identity is made salient (Steele, 1997). Schmader and Johns (2003) found evidence for a stereotype threat effect among Latinos and women when an achievement test was framed in terms of tests of intelligence or mathematical ability. They suggested that stereotype threat reduces performance on complex cognitive tasks because priming negative stereotypes interferes with attentional resources as measured by performance on a working memory task. We would add to this explanation that stereotype threats probably lead to distracting thoughts about one's relational value and social acceptance as well. Importantly, providing feedback that improves minority students' sense of belonging in academic settings has been found to improve their motivation and achievement (Walton \& Cohen, 2007).

Twenge et al. (2003) suggested that some of the dysregulative effects of rejection may arise from a state of "cognitive deconstruction" that is marked by a lack of emotion, an altered sense of time, immersion in the present rather than the past or future, and a lower amount of meaningful thought. Some such effects may reflect excessive preoccupation with the rejection episode, and others may involve efforts to avoid self-awareness and the emotional distress evoked by rejection and other unpleasant experiences. In one study, participants who were led to expect that they would be alone later in life chose seats that faced away from a mirror more than did nonexcluded participants, suggesting efforts to avoid self-awareness when rejection is salient (Twenge et al., 
2003, Experiment 6). We should note that not all types of cognitive performance are compromised, however. As described earlier, rejection leads to improved performance on tasks involving the detection and interpretation of social cues (Gardner et al., 2000; Pickett et al., 2004).

\section{Summary}

Our theoretical model predicts that rejection episodes that are construed as unfair and/or occur in the context of a relationship that is not valued reliably lead people to become angry and aggressive and to act in ways that generally reduce rather than augment their social desirability and relational value. These behaviors are probably multiply determined and fueled by anger, revenge motives, cognitive distraction, self-regulatory problems, and other factors. Future research needs to take an increasingly nuanced approach to understanding the precise causes of the antisocial reactions that have been observed.

\section{Withdrawal and Avoidance}

A third, although less widely studied, reaction to rejection involves withdrawal. In addition to bolstering their social connections and behaving antisocially, people who are rejected sometimes withdraw from and avoid interpersonal interactions, not only with those who rejected them but often with other people as well. In some cases, they physically leave the situation entirely, but they may also withdraw socially and psychologically while remaining physically present when they cannot escape or avoid social encounters. These responses are most likely to occur when there is a low expectation of relationship repair, the relationship is not highly valued, there are possibilities for alternatives, and the rejection is chronic or pervasive.

As Vangelisti (2001) observed, a core feature of feeling hurt by rejection is a sense of vulnerability. People who have been rejected understandably do not wish to be hurt further, and their fear of being hurt may lead them to distance themselves both from the person who rejected them and from other people whose acceptance they do not fully trust (Vangelisti et al., 2005). The degree to which rejection by one person leads people to distance themselves from other, uninvolved individuals may be influenced by the degree to which people interpret the rejection as a reflection of their general relational value or social acceptability as opposed to an isolated, relationship-specific event.

Little research has directly examined the effects of perceived rejection on avoidance and withdrawal, but indirect evidence suggests that people who are concerned about acceptance sometimes distance themselves from other people. For example, despite desiring social connections, people who feel lonely are less responsive to others during discussions (C. M. Anderson \& Martin, 1995) and are less accepting of potential new friends (Rotsenberg \& Kmill, 1992). Likewise, when people feel socially anxious-a reaction that stems from concerns with other people's impressions and acceptance - they often avoid interacting with other people (Dodge, Heimberg, Nyman, \& O'Brien, 1987). Furthermore, when they must interact, people who are high in social anxiety behave in an inhibited, withdrawn, reticent fashion, particularly when they think that they are being evaluated (DePaulo, Epstein, \& LeMay, 1990). Although situations that elicit social anxiety do not neces- sarily include explicitly rejecting feedback from others, people who feel socially anxious are fundamentally concerned about others' evaluations and acceptance of them.

In one of the few experimental studies of behavioral reactions to rejection, Waldrip and Jensen-Campbell (2007) found that participants who interacted with a person who had previously preferred to interact with another participant instead of them sat further away from the person and oriented their bodies away from him or her. (They did not differ in amount of eye contact, however.) Furthermore, excluded participants expressed a stronger dread of interacting with the person and a lower desire to communicate with him or her as well.

In an analysis of interracial interactions, Shelton and Richeson (2006) noted that having a stigmatized status and experiencing chronic rejection may shape meta-perceptions regarding others' reactions and lead to wariness regarding interactions in which one might be devalued or rejected. Research on interracial interactions finds that, when the possibility for devaluation is salient, the perception of potential prejudice affects how people feel about and behave during the interaction. Shelton and Richeson reviewed evidence showing that placing ethnic minorities in a situation with a high possibility that they could be the target of prejudice influences their affective reactions about an anticipated interaction, as well as their feelings about future interactions. When this possibility is explicit (as in one study where Latino and Asian American participants believed that a future interaction partner held prejudiced beliefs about their groups), participants reported feeling more hostile and anxious about the anticipated interaction and less positive about interacting with outgroup members in general, compared to those who anticipated interacting with someone who had race-neutral beliefs (Tropp \& Wright, 2003). Compensatory strategies may be employed to smooth out interactions (e.g., Shelton et al., 2004), but avoiding such interactions may be a simpler strategy over time. Often such concerns about how they will be treated by outgroup members may be an important reason why interracial interactions occur so rarely and meaningful interracial relationships are still uncommon.

Several considerations may enter into this withdrawal pattern that may undermine acceptance and stymie the development of social connections. First, from a purely pragmatic standpoint, people often see little value in interacting with those who do not adequately accept them. As a result, withdrawal and avoidance is perhaps most likely when people do not expect that further interaction will lead to acceptance. As Maner et al. (2007) showed, people are specific in not wanting future interactions with those who rejected them but may seek opportunities to interact with others who were not involved in the rejection.

Furthermore, continued interaction with someone who has rejected the individual raises the threat of further rejection and hurt. Thus, withdrawal may be motivated by a desire to avoid additional decrements in belonging and the accompanying emotional pain. This consideration may even lead people to avoid interacting with those who were not involved in the initial rejection episode unless their acceptance is assured. Once they are rejected by one person, people may temporarily lose confidence in their acceptability to others.

Doubts about one's relational value and acceptability to other people are particularly pronounced when the person was rejected due to an impropriety, indiscretion, transgression, malfeasance, or 
other misbehavior on his or her part. Thus, it is not surprising that people who feel ashamed of something they have done typically display a strong urge to withdraw from social contact. Research shows that the experience of shame is associated with a strong desire to escape, hide, or disappear (Ferguson, Stegge, \& Damhuis, 1991; Tangney, Miller, Flicker, \& Barlow, 1996). In part, this urge to withdraw may stem from the fact that shame arises when people make a strong internal attribution for an undesired behavior that has moral connotations, thus denigrating themselves as reprehensible, worthless, and inferior. Understandably, people who feel worthless or despicable are likely to believe that others will reject them and that little can be done to restore their relational value. As a result, they are motivated to avoid interacting with other people who are likely to condemn them. This shame response stands in contrast to people's reactions when they feel guilty, in which people recognize that they have performed a bad behavior but do not strongly denigrate themselves and are motivated to repair the damage rather than to withdraw (Tangney, 2003).

Shame is often also accompanied by anger and aggression. Numerous studies have shown that people report becoming angry in shame-eliciting situations and that people who are particularly prone to shame report greater hostility and anger than those who are less prone to shame (Tangney et al., 1996; Tangney, Wagner, Fletcher, \& Gramzow, 1992). Paradoxically, although people experiencing shame condemn themselves for being a bad person, they also blame other people or the situation for their plight and become angry (Tangney, 2003). Thus, when people who are rejected also feel shame they may display both antisocial urges and a desire to withdraw.

\section{Dispositional Moderators}

Although features of the rejection episode and the nature of people's social lives affect how they respond to rejection, people differ in the degree to which they react to negative interpersonal events in a predominately positive, negative, or avoidant fashion. Here we mention two personality characteristics that predict which course of action people take after rejection.

\section{Agreeableness and Hostility}

Agreeableness, one of the Big Five personality traits, is associated with the motive to strive for closeness and solidarity with other people, a desire to maintain positive interpersonal relationships, the ability to inhibit negative affect in social situations (presumably so as not to alienate others), and an abiding prosocial orientation (Graziano \& Eisenberg, 1997). The opposite pole of agreeableness is characterized by unfriendliness, self-interest, and hostility. (Thus, research that has focused on "hostility" can be viewed as dealing, at least in part, with low agreeableness.) High agreeableness should be associated with stronger prosocial responses, or at least muted antisocial and avoidant reactions, in the face of interpersonal rejection.

Agreeable people may perceive less rejection in their social worlds than those who are less agreeable. People who are high in agreeableness are perceived in more socially desirable ways, are liked more, and work harder to maintain positive relationships, thereby leading them to be more accepted (Graziano, JensenCampbell, \& Hair, 1996; Jensen-Campbell et al., 2002). In addi- tion, agreeable people like and trust others more, perceive other people in more socially desirable ways, and perceive less conflict in social situations (Graziano \& Eisenberg, 1997; Graziano et al., 1996; Jensen-Campbell \& Graziano, 2001).

When others do ignore, shun, criticize, reject, or otherwise devalue them, agreeable people respond in a more temperate manner. In particular, high agreeableness is associated with lower argumentativeness, anger, hurt feelings, and aggression in difficult interpersonal encounters (Gleason, Jensen-Campbell, \& Richardson, 2004; Jensen-Campbell \& Graziano, 2001; Meier \& Robinson, 2004). Furthermore, when disagreements and conflicts arise, agreeable people are more likely to use constructive tactics such as forgiving other people's misbehaviors (Jensen-Campbell \& Graziano, 2001; McCullough \& Hoty, 2002; Strelan, 2007). Being motivated to maintain positive relationships short-circuits the spiral of escalating negative reactions that often occurs when people perceive that others are rejecting them.

\section{Self-Esteem}

Trait self-esteem is strongly associated with a belief in one's general social acceptability. In fact, one of the best predictors of self-esteem is the degree to which people believe that they are approved of and accepted by other people (Leary \& MacDonald, 2003). Not surprisingly, then, people who are low versus high in self-esteem respond differently to rejection. Interestingly, however, high self-esteem may be associated with two distinct and sometimes competing reactions. On one hand, because people who are high in self-esteem feel more generally acceptable than those who are low in it, they may find interpersonal rejections more surprising and, often, more unjustified, thereby leading to consternation and anger. On the other hand, because they feel more globally acceptable, they perceive their social opportunities and alternatives to be greater, which should lessen the impact of any particular rejection. These competing effects may explain why research that has examined the moderating effects of trait selfesteem on reactions to rejection (as well as other events that raise the specter of rejection, such as social-evaluative threats, criticism, and failure) has obtained conflicting results. In some studies, people with high self-esteem appear to react more strongly to rejection, whereas in other studies they seem to react less strongly (for a review, see Sommer, 2001).

\section{Summary}

Many factors combine to influence the degree to which people respond in a prosocial, antisocial, or avoidant manner when they feel rejected. The likelihood of prosocial responses is heightened by perceiving that the probability of restoring the relationship is high, placing a high value on the relationship, and perceived costs associated with further damage to or loss of the relationship, and high agreeableness. The probability of antisocial reactions is increased by perceiving that one was treated unfairly and low agreeableness (or hostility). The tendency toward withdrawal is associated with a high number of perceived alternatives, chronic rejection, and low self-esteem. It should be noted that the construal process that mediates these responses is not always conscious and deliberative. In the wake of a romantic rejection for instance, the possibility of alternative relationships may weigh heavily on the 
decision to try to win this person back or move on to other options, but these calculations may not necessarily be conscious.

In identifying the construals that mediate people's reactions to rejection, our model differs from K. D. Williams's (2001, 2007) proposal that people's reactions are predicted by the nature of the need(s) that are most threatened by a particular rejection episode. As noted earlier, we agree with Williams that rejection-related experiences can have multiple effects and, like any complex negative event, threaten many aspects of people's well-being. Yet, we think that it is important to distinguish the effects of low relational value (i.e., threatened acceptance or belonging) from the effects of other features of the episode that are not specific to rejection per se (such as whether people experience a loss of control, meaning, or perhaps self-esteem).

\section{Discussion}

People's reactions to perceiving that they are inadequately valued and accepted by others involve a complex, interactive, dynamic system of cognitive, emotional, motivational, and behavioral responses. Although no conceptual model could possibly capture the complexity or fullness of people's responses to perceived rejection, we believe that our approach provides a broad and nuanced framework for describing and explaining why people think, feel, and behave as they do when they perceive that others have rejected them. We suggest that the ways in which people react are influenced by their construals of the rejection experience that predict motives for prosocial, antisocial, and socially avoidant responses.

\section{The Complexity of Real-Life Rejection Episodes}

The complexity of people's reactions to rejection arises from five fundamental features portrayed in our model. First, as we have seen, rejection episodes typically elicit three quite different motives. As Maner et al. (2007) observed, rejection leads people to be both needy (in terms of desiring acceptance) and vulnerable (in terms of fearing future hurt), and we would add that they are often indignant and angry as well. In isolation, each of these motives serves an important function-repairing social connections, punishing or deterring the rejector, and avoiding further rejection and hurt. But, as we have seen, the behaviors that serve these various motives are often at odds with one another. Actions that reestablish connections may open one up for further rejection, angry and aggressive responses often damage social bonds, trying to protect oneself from further pain leads to social disengagement that thwarts the development of new relationships, and so on. Recognizing that people who feel rejected may be motivated to achieve three quite disparate goals helps to explain the variety of ways in which they respond and accounts for certain inconsistencies in the rejection literature.

Second, we propose in our model that one motive typically dominates a person's attention and actions at any particular moment, but it is important to stress that the others are usually not far below the surface. When people perceive that there is a high probability of restoring their relationship, prosocial responses should occur, but if this assessment were to change, then more antisocial responses would be predicted. For example, a man whose girlfriend has left him may initially perceive some likeli- hood of getting back together and, thus, be on especially good behavior. But, as it becomes clearer that she does not intend to return, he may behave in an increasingly antisocial fashion, finally withdrawing from all contact when it is clear that the relationship is over. Likewise, in extreme cases of rejection-induced aggression, such as school shootings, the ostracized student may initially try to behave in ways that promote acceptance. Only after repeated efforts are rebuffed does he or she turn simultaneously to withdrawal and aggression. A limitation of much of the rejectionrelated research to date is that typically only one category of responses is measured, so the interplay of these reactions is, as of yet, unknown. More longitudinal research is needed on the aftermath of rejection, and such research should examine the trajectories of these three motives, along with associated emotions and behaviors.

Third, to complicate matters further, each of the three motives can be fulfilled by a wide variety of specific actions, which presumably depend on not only the construals proposed in our model but also an array of relational, contextual, and dispositional variables. The nature of the preexisting relationship between the rejector and rejectee, the individual's assessment of the likely effects of particular reactions given the rejector's characteristics and the social context, and judgments of one's own social value and interpersonal skills should determine precisely how people will respond when they feel rejected. Identifying how these variables influence responses to a range of rejection-related experiences allows for the opportunity to integrate the various rejectionrelated literatures and make sense of the commonalities and differences among them.

Fourth, the unfolding of a person's reactions after rejection depends in large part on how other people respond to him or her. Behaving prosocially may help to restore a social bond, but it may also lead to rebuff, distancing, ridicule, and even more adamant rejection. Expressing hurt or anger might lead a rejector to change his or her mind, but it is just as likely to result in an escalating cycle of anger, criticism, and possibly violence. Withdrawal may lead other people to provide support but may also isolate the person from social contact. Thus, a complete understanding of the aftermath of rejection requires attention to how other peopleboth those immediately involved in the episode and those who were not involved-respond to the rejected individual's reactions.

Finally, the process of dealing with rejection is affected by factors that operate outside of the rejection episode itself. Other people, who have nothing whatsoever to do with the focal rejection event, can exert a pronounced influence on how the rejected person reacts to rejection. For example, a heart-broken lover who is locked in a cycle of desperate actions to win the beloved back may suddenly and unexpectedly meet someone with whom a new relationship flourishes. Or, a member of a stigmatized racial or ethnic group may become friends with a member of the majority group, who provides a new perspective on his or her experiences. Or, someone fired from a job may spiral into greater despair if this rejection is soon followed a marital separation or a fracture in a close friendship. Virtually all research on rejection experiences has examined isolated experiences of devaluation in the laboratory or the real world, but real rejections occur within a complex system of other influences. 


\section{Future Directions}

As we have seen, the process of dealing with rejections involves innumerable complexities. Even so, we believe that our model identifies most of the critical elements and identifies areas for future investigation. Specifically, we see many gaps in our understanding of the sequelae of interpersonal rejection. To conclude, we describe three directions for future research that we believe may be most fruitful at this time.

We began with the assertion that interpersonal rejection has been studied under the guise of several different phenomena, such as ostracism, prejudice, stigmatization, neglect, peer rejection, romantic breakups, discrimination, betrayal, and so on, all of which share the common feature of involving threats to a sense of relational value, belonging, and acceptance. In light of this fact, research is needed that examines the common and distinct features of these phenomena vis-à-vis rejection. Viewed in one way, these experiences share a common theme of threatened belonging, and many of people's reactions across these situations may reflect responses to perceived relational devaluation and rejection. At the same time, rejections that occur in different kinds of relationships and on the basis of different criteria undoubtedly differ from one another. Careful investigations of the similarities and differences in how people respond to the rejections involved in stigmatization, prejudice, romantic splits, and other disparate events will help to develop a broader understanding of the effects of perceived rejection.

As we have noted, reactions to rejection episodes unfold over time, and work is needed to understand the temporal features of this process. K. D. Williams $(1997,2001,2007)$ has discussed the ways in which reactions to ostracism might play out over time, and his model provides an excellent starting point for future work on this topic. Of course, incorporating time as a factor in psychological theories and research is quite difficult, and we expect that progress in this vein may be slow. However, the snapshots provided by experimental studies and the retrospective accounts of rejection collected in correlational research provide little insight into how people cope with rejection over time. Although limited research has been conducted on the longitudinal effects of these experiences, evidence suggests that chronic deprivation of belonging leads to prolonged negative affect (particularly depression, loneliness, and anger) and negative physical health outcomes either directly through chronic activation of stress responses or through behaviors that increase the risk for health problems. Given that failure to deal successfully with rejection has long-term psychological and physical consequences, research is needed to understand factors that influence the temporal trajectory of coping with rejection for both theoretical and clinical reasons.

Our review of the broad rejection literature finds that people have a varied and vast array of coping mechanisms for attempting to restore belonging following rejection. In many cases, such restoration is not possible with the individual, group, or even society that perpetrated the rejection, but our review finds that people often seek alternative sources of acceptance through developing new relationships, fostering stronger ties with a stigmatized group, or using other strategies to remind themselves of important relationships and to feel a temporary sense of belonging. Future research that examines how people recover from rejection experi- ences would benefit from including measures of multiple strategies that people can employ.

In conclusion, we have provided a framework for integrating the diverse literatures on rejection-related experiences. Given the importance of acceptance and belonging to psychological and physical well-being, people understandably devote a great deal of attention and effort to their interpersonal relationships, and their reactions to perceived devaluation and rejection involve a complex interplay of construals, motives, emotions, dispositions, and behaviors. Following rejection, people are influenced by construals of the rejection episode that predict their motivated responses toward the rejector. These responses fulfill certain relational goals but also prompt behaviors that can be counterproductive to satisfying belonging needs. Various factors affect the likelihood of which motive will determine people's responses to a rejection experience at any particular time and, thus, how the aftermath of a rejection unfolds. Often rejection episodes end quickly, but sometimes long-term negative outcomes arise that are associated with the stress of chronic rejection, prolonged lack of opportunities for acceptance, or ineffective attempts to restore belonging. Psychological and physical well-being rests on people's ability to cope with and resolve rejection experiences, and we hope that our review and theoretical framework provides an effective approach for considering the myriad factors that influence people's shortand long-term reactions to interpersonal rejection.

\section{References}

Abrams, D., Hogg, M. A., \& Marques, J. M. (2005). The social psychology of inclusion and exclusion. New York: Psychology Press.

Anderson, C. M., \& Martin, M. M. (1995). The effects of communication motives, interaction involvement, and loneliness on satisfaction. Small Group Research, 26, 118-137.

Anderson, E. R., Greene, S. M., Walker, L., Malerba, C. A., Forgatch, M. S., \& DeGarmo, O. S. (2004). Ready to take a chance again: Transitions into dating among divorced parents. Journal of Divorce and Remarriage, 40, 61-75.

Asher, S. R., \& Coie, J. D. (1990). Peer rejection in childhood. New York: Cambridge University Press.

Asher, S. R., Rose, A. J., \& Gabriel, S. W. (2001). Peer rejection in everyday life. In M. R. Leary (Ed.), Interpersonal rejection (pp. 105142). New York: Oxford University Press.

Ayduk, O., Downey, G., Testa, A., \& Yen, Y. (1999). Does rejection elicit hostility in rejection sensitive women? Social Cognition, 17, 245-271.

Barnard, G. W., Vera, H., Vera, M. I., \& Newman, G. (1982). Till death do us part: A study of spouse murder. Bulletin of the American Academy of Psychiatry and the Law, 10, 271-280.

Baumeister, R. F., \& DeWall, C. N. (2005). Inner disruption following social exclusion: Reduced intelligent thought and self-regulation failure. In K. D. Williams \& W. von Hippel (Eds.), The social outcast: Ostracism, social exclusion, rejection, and bullying (pp. 53-73). New York: Psychology Press.

Baumeister, R. F., DeWall, C. N., Ciarocco, N. J., \& Twenge, J. M. (2005). Social exclusion impairs self-regulation. Journal of Personality and Social Psychology, 88, 589-604.

Baumeister, R. F., \& Leary, M. R. (1995). The need to belong: Desire for interpersonal attachments as a fundamental human motivation. Psychological Bulletin, 117, 497-529.

Baumeister, R. F., Twenge, J. M., \& Nuss, C. K. (2002). Effects of social exclusion on cognitive processes: Anticipated aloneness reduces intelligent thought. Journal of Personality and Social Psychology, 83, 817827. 
Baumeister, R. F., Wotman, S. R., \& Stillwell, A. M. (1993). Unrequited love: On heartbreak, anger, guilt, scriptlessness, and humiliation. Journal of Personality and Social Psychology, 64, 377-394.

Bettencourt, B. A., Tally, A., Benjamin, A. J., \& Valentine, J. (2006). Personality and aggressive behavior under provoking and neutral conditions: A meta-analytic review. Psychological Bulletin, 132, 751-777.

Blackhart, G. C., Eckel, L. A., \& Tice, D. M. (2007). Salivary cortisol in response to acute social rejection and acceptance by peers. Biological Psychology, 75, 267-276.

Blackhart, G. C., Knowles, M. L., \& Bieda, K. (2007). A meta-analytic review of affective reactions and self-esteem in response to social rejection: Support for the belongingness and sociometer theories. Manuscript submitted for publication.

Borrell, L. N., Jacobs, D. R., Williams, D. R., Pletcher, M. J., Houston, T. K., \& Kiefe, C. I. (2007). Self-reported racial discrimination and substance use in the coronary artery risk development in adults study. American Journal of Epidemiology, 166, 1068-1079.

Bourgeois, K. S., \& Leary, M. R. (2001). Coping with rejection: Derogating those who choose us last. Motivation and Emotion, 25, 101-111.

Buckley, K. E., Winkel, R. E., \& Leary, M. R. (2004). Reactions to acceptance and rejection: Effects of level and sequence of relational evaluation. Journal of Experimental Social Psychology, 40, 14-28.

Carvallo, M., \& Pelham, B. W. (2006). When fiends become friends: The need to belong and perceptions of personal and group discrimination. Journal of Personality and Social Psychology, 90, 94-108.

Chartrand, T. L., \& Bargh, J. A. (1999). The chameleon effect: The perception-behavior link and social interaction. Journal of Personality and Social Psychology, 76, 893-910.

Chen, Z., Williams, K. D., Fitness, J., \& Newton, N. C. (2008). When hurt will not heal: Exploring the capacity to relive social and physical pain. Psychological Science, 19, 789-795.

Clark, R. (2006). Perceived racism and vascular reactivity in Black college women: Moderating effects of seeking social support. Health Psychology, 25, 20-25.

Cohen, S., \& Wills, T. A. (1985). Stress, social support, and the buffering hypothesis. Psychological Bulletin, 98, 310-357.

Crawford, M., \& Gartner, R. (1992). Women killing: Intimate femicide in Ontario, 1974-1990. Toronto, Ontario, Canada: Women We Honour Action Committee.

DeCremer, D., \& Leonardelli, G. J. (2003). Cooperation in social dilemmas and the need to belong: The moderating effect of group size. Group Dynamics: Theory, Research, and Practice, 7, 168-174.

DePaulo, B. M., Epstein, J. A., \& LeMay, C. S. (1990). Responses of the socially anxious to the prospect of interpersonal evaluation. Journal of Personality, 48, 623-640.

DeWall, C. N., \& Baumeister, R. F. (2006). Alone but feeling no pain: Effects of social exclusion on physical pain tolerance and pain threshold, affective forecasting, and interpersonal empathy. Journal of Personality and Social Psychology, 91, 1-15.

Dion, K. L., \& Earn, B. M. (1995). The phenomenology of being a target of prejudice. Journal of Personality and Social Psychology, 32, 944950.

Dodge, C. S., Heimberg, R. G., Nyman, D., \& O’Brien, G. T. (1987). Daily heterosocial interactions of high and low socially anxious college students: A diary study. Behavior Therapy, 18, 90-96.

Downey, G., \& Feldman, S. I. (1996). Implications of rejection sensitivity for intimate relationships. Journal of Personality and Social Psychology, 70, 1327-1343.

Downey, G., Freitas, A. L., Michaelis, B., \& Khouri, H. (1998). The self-fulfilling prophecy in close relationships: Rejection sensitivity and rejection by romantic partners. Journal of Personality and Social Psychology, 75, 545-560.

Eisenberger, N. I., Lieberman, M. D., \& Williams, K. D. (2003, October
10). Does rejection hurt? An fMRI study of social exclusion. Science, 302, 290-292.

Epley, N., Waytz, A., \& Cacioppo, J. T. (2007). On seeing human: A three-factor theory of anthropomorphism. Psychological Bulletin, 114, $864-886$.

Ferguson, T. J., Stegge, H., \& Damhuis, I. (1991). Children's understanding of guilt and shame. Child Development, 62, 827-839.

Gardner, W., Jefferis, V. E., \& Knowles, M. L. (in press). Never alone: The interdependent self as a buffer from rejection. Journal of Personality and Social Psychology.

Gardner, W. L., Pickett, C. L., \& Brewer, M. B. (2000). Social exclusion and selective memory: How the need to belong influences memory for social events. Personality and Social Psychology Bulletin, 26, 486-496.

Gardner, W. L., Pickett, C. L., Jefferis, V., \& Knowles, M. (2005). On the outside looking in: Loneliness and social monitoring. Personality and Social Psychology Bulletin, 31, 1549-1560.

Gibbons, F. X., Gerrard, M., Cleveland, M. J., Wills, T. A., \& Brody, G. H. (2004). Perceived discrimination and substance use in African American parents and their children: A panel study. Journal of Personality and Social Psychology, 86, 517-529.

Gleason, K. A., Jensen-Campbell, L. A., \& Richardson, D. (2004). Agreeableness and aggression in adolescence. Aggressive Behavior, 30, $43-$ 61.

Graziano, W. G., \& Eisenberg, N. (1997). Agreeableness: A dimension of personality. In R. Hogan, S. Briggs, \& J. Johnson (Eds.), Handbook of personality psychology (pp. 795-824). San Diego, CA: Academic Press.

Graziano, W. G., Jensen-Campbell, L. A., \& Hair, E. C. (1996). Perceiving interpersonal conflict and reacting to it: The case for agreeableness. Journal of Personality and Social Psychology, 70, 820-835.

Hardin, C. D., \& Conley, T. D. (2001). A relational approach to cognition: Shared experience and relationship affirmation in social cognition. In G. B. Moskowitz (Ed.), Cognitive social psychology: The Princeton Symposium on the legacy and future of social cognition (pp. 3-21). Mahwah, NJ: Erlbaum.

Holahan, C. J., \& Moos, R. H. (1985). Life stress and health: Personality, coping, and family support in stress resistance. Journal of Personality and Social Psychology, 49, 739-747.

Inzlicht, M., McKay, L., \& Aronson, J. (2006). Stigma as ego depletion: How being the target of prejudice affects self-control. Psychological Science, 17, 262-269.

Jensen-Campbell, L. A., Adams, R., Perry, D., Furdella, J. Q., Workman, K. A., \& Egan, S. (2002). Agreeableness, extraversion, and peer relations in early adolescence: Winning friends and deflecting aggression. Journal of Research in Personality, 36, 224-251.

Jensen-Campbell, L. A., \& Graziano, W. G. (2001). Agreeableness as a moderator of interpersonal conflict. Journal of Personality, 69, 323-362.

Kleck, R. E., \& Strenta, A. (1980). Perceptions of the impact of negatively valued physical characteristics on social interaction. Journal of Personality and Social Psychology, 39, 861-873.

Koenig, F., \& Lessan, G. (1985). Viewers' relationship to television personalities. Psychological Reports, 57, 263-266.

Kupersmidt, J. B., Burchinal, M., \& Patterson, C. J. (1995). Developmental patterns of childhood peer relations as predictors of externalizing behavior problems. Development and Psychopathology, 7, 825-843.

Lakin, J., \& Chartrand, T. L. (2003). Increasing nonconscious mimicry to achieve rapport. Psychological Science, 27, 145-162.

Landrine, H., \& Klonoff, E. A. (1996). The schedule of racist events: A measure of racial discrimination and a study of its negative physical and mental health consequences. Journal of Black Psychology, 22(2), 144 168.

Leary, M. R. (Ed.). (2001). Interpersonal rejection. New York: Oxford University Press.

Leary, M. R. (2006). Sociometer theory and the pursuit of relational value: 
Getting to the root of self-esteem. European Review of Social Psychology, 16, 75-111.

Leary, M. R. (2007). Motivational and emotional aspects of the self. Annual Review of Psychology, 58, 317-344.

Leary, M. R., \& Baumeister, R. F. (2000). The nature and function of self-esteem: Sociometer theory. In M. P. Zanna (Ed.), Advances in experimental social psychology (Vol. 32, pp. 1-62). San Diego, CA: Academic Press.

Leary, M. R., Cottrell, C. A., \& Phillips, M. (2001). Deconfounding the effects of dominance and social acceptance on self-esteem. Journal of Personality and Social Psychology, 81, 898-909.

Leary, M. R., Gallagher, B., Fors, E. H., Buttermore, N., Baldwin, E., Lane, K. K., \& Mills, A. (2003). The invalidity of personal claims about self-esteem. Personality and Social Psychology Bulletin, 29, 623-636.

Leary, M. R., Haupt, A. L., Strausser, K. S., \& Chokel, J. T. (1998). Calibrating the sociometer: The relationship between interpersonal appraisals and state self-esteem. Journal of Personality and Social Psychology, 74, 1290-1299.

Leary, M. R., Koch, E., \& Hechenbleikner, N. (2001). Emotional responses to interpersonal rejection. In M. R. Leary (Ed.), Interpersonal rejection (pp. 145-166). New York: Oxford University Press.

Leary, M. R., Kowalski, R. M., Smith, L., \& Phillips, S. (2003). Teasing, rejection, and violence: Case studies of the school shootings. Aggressive Behavior, 29, 202-214.

Leary, M. R., \& Leder, S. (in press). The nature of hurt feelings: Emotional experience and cognitive appraisals. In A. Vangelisti (Ed.), Feeling hurt in close relationships. New York: Cambridge University Press.

Leary, M. R., \& MacDonald, G. (2003). Individual differences in selfesteem: A review and theoretical integration. In M. R. Leary \& J. P. Tangney (Eds.), Handbook of self and identity (pp. 401-418). New York: Guilford Press.

Leary, M. R., \& Springer, C. (2000). Hurt feelings: The neglected emotion. In R. M. Kowalski (Ed.), Behaving badly: Aversive behaviors in interpersonal relationships (pp. 151-175). Washington, DC: American Psychological Association.

Leary, M. R., Tambor, E. S., Terdal, S. K., \& Downs, D. L. (1995). Self-esteem as an interpersonal monitor: The sociometer hypothesis. Journal of Personality and Social Psychology, 68, 518-530.

Leary, M. R., Twenge, J. M., \& Quinlivan, E. (2006). Interpersonal rejection as a determinant of anger and aggression. Personality and Social Psychology Review, 10, 111-132.

Lind, E. A., \& Tyler, T. R. (1988). The social psychology of procedural justice. New York: Plenum Press.

MacDonald, G. (in press). Social pain and hurt feelings. In P. J. Corr \& G. Matthews (Eds.), Cambridge handbook of personality psychology. New York: Cambridge University Press.

MacDonald, G., \& Leary, M. R. (2005). Why does social exclusion hurt? The relationship between social and physical pain. Psychological Bulletin, 131, 202-223.

Major, B., Spencer, S., Schmader, T., Wolfe, C., \& Crocker, J. (1998). Coping with negative stereotypes about intellectual performance: The role of psychological disengagement. Personality and Social Psychology Bulletin, 24, 34-50.

Maner, J. K., DeWall, C. N., Baumeister, R. F., \& Schaller, M. (2007). Does social exclusion motivate interpersonal reconnection? Resolving the "porcupine problem." Journal of Personality and Social Psychology, 92, 42-55.

McConahay, J. B. (1986). Modern racism, ambivalence, and the Modern Racism Scale. In J. F. Dovidio \& S. L. Gaertner (Eds.), Prejudice, discrimination, and racism (pp. 91-125). San Diego, CA: Academic Press.

McCullough, M. E., \& Hoty, W. T. (2002). Transgression-related motivational dispositions: Personality substrates of forgiveness and their links to the Big Five. Personality and Social Psychology Bulletin, 28, 15561573.

McDougall, P., Hymel, S., Vaillancourt, T., \& Mercer, L. (2001). The consequences of childhood peer rejection. In M. R. Leary (Ed.), Interpersonal rejection (pp. 213-247). New York: Oxford University Press.

Meier, B. P., \& Robinson. M. D. (2004). Does quick to blame mean quick to anger? The role of agreeableness in dissociating blame and anger. Personality and Social Psychology Bulletin, 30, 856-867.

Miller, C., Rothblum, E. D., Felicio, D., \& Brand, P. (1995). Do obese women have poorer social relationships than nonobese women? Personality and Social Psychology Bulletin, 21, 1093-1106.

Miller, D. T. (2001). Disrespect and the experience of injustice. Annual Review of Psychology, 52, 527-553.

Mills, R. S. L., Nazar, J., \& Farrell, H. M. (2002). Child and parent perceptions of hurtful messages. Journal of Social and Personal Relationships, 19, 731-754.

Murray, S. L., Griffin, D. W., Rose, P., \& Bellavia, G. (2003). Calibrating the sociometer: The relational contingencies of self-esteem. Journal of Personality and Social Psychology, 85, 63-84.

Murray, S. L., \& Holmes, J. G. (2000). Seeing the self through a partner's eyes: Why self-doubts turn into relationship insecurities. In A. Tesser, R. B. Felson, \& J. M. Suls (Eds.), Psychological perspectives on self and identity (pp. 173-197). Washington, DC: American Psychological Association.

Murray, S. L., Holmes, J. G., \& Griffin, D. W. (2000). Self-esteem and the quest for felt security: How perceived regard regulates attachment processes. Journal of Personality and Social Psychology, 78, 478-498.

Nezlek, J. B., Kowalski, R. M., Leary, M. R., Blevins, T., \& Holgate, S. (1997). Personality moderators of reactions to interpersonal rejection: Depression and trait self-esteem. Personality and Social Psychology Bulletin, 23, 1235-1244.

Noh, S., \& Kasper, V. (2003). Perceived discrimination and depression: Moderating effects of coping, acculturation, and ethnic support. American Journal of Public Health, 93, 232-238.

Ouwerkerk, J. W., Kerr, N. L., Gallucci, M., \& Van Lange, P. (2005). Avoiding the social death penalty: Ostracism and cooperation in social dilemmas. In K. D. Williams \& W. von Hippel (Eds.), The social outcast: Ostracism, social exclusion, rejection, and bullying (pp. 321332). New York: Psychology Press.

Pascoe, E., \& Smart Richman, L. (2008). Perceived discrimination and health: A meta-analytic review. Manuscript submitted for publication.

Pederson, W. C., Gonzales, C., \& Miller, N. (2000). The moderating effect of trivial triggering provocation on displaced aggression. Journal of Personality and Social Psychology, 78, 913-927.

Perse, E. M., \& Rubin, R. B. (1989). Attribution in social and parasocial relationships. Communication Research, 16, 59-77.

Pickett, C. L., \& Gardner, W. L. (2005). The social monitoring system: Enhanced sensitivity to social cues as an adaptive response to social exclusion. In K. Williams, J. Forgas, \& W. von Hippel (Eds.), The social outcast: Ostracism, social exclusion, rejection, and bullying (pp. 213225). New York: Psychology Press.

Pickett, C. L., Gardner, W. L., \& Knowles, M. (2004). Getting a cue: The need to belong and enhanced sensitivity to social cues. Personality and Social Psychology Bulletin, 30, 1095-1107.

Pressman, S., \& Cohen, S. (2005). Does positive affect influence health? Psychological Bulletin, 131, 925-971.

Prinstein, M. J., \& Aikins, J. W. (2004). Cognitive moderators of the longitudinal association between peer rejection and adolescents' depressive symptoms. Journal of Abnormal Child Psychology, 32, 147-158.

Reijntjes, A. S., Stegge, H., Terwogt, M. M., Kamphuis, J. H., \& Telch, M. J. (2006). Emotion regulation and its effects on mood improvement in response to an in vivo peer rejection challenge. Emotion, 6, 543-552. Rotsenberg, K. J., \& Kmill, J. (1992). Perception of lonely and non-lonely 
persons as a function of individual differences in loneliness. Journal of Social and Personal Relationships, 9, 325-330.

Rubin, A. M., Perse, E. M., \& Powell, R. A. (1985). Loneliness, parasocial interaction, and local television news viewing. Human Communication Research, 12, 155-180.

Rusbult, C. E. (1980). Commitment and satisfaction in romantic associations: A test of the investment model. Journal of Experimental Social Psychology, 16, 172-186.

Schimel, J., Arndt, J., Banko, K. M., \& Cook, A. (2004). Not all selfaffirmations were created equal: The cognitive and social benefits of affirming the intrinsic (vs. extrinsic) self. Social Cognition, 22, 75-99.

Schmader, T., \& Johns, M. (2003). Converging evidence that stereotype threat reduces working memory capacity. Journal of Personality and Social Psychology, 85, 440-452.

Schmitt, M. T., \& Branscombe, N. L. (2002). The meaning and consequences of perceived discrimination in disadvantaged and privileged social groups. European Review of Social Psychology, 12, 167-199.

Sellers, R. M., \& Shelton, J. N. (2003). The role of racial identity in perceived racial discrimination. Journal of Personality and Social Psychology, 84, 1079-1092

Shaver, P. R., Schwartz, J., Kirson, D., \& O’Conner, C. (1987). Emotion knowledge: Further exploration of a prototype approach. Journal of Personality and Social Psychology, 52, 1061-1086.

Shelton, J. N., \& Richeson, J. A. (2006). Interracial interactions: A relational approach. Advances in Experimental Social Psychology, 38, 121181.

Shelton, J. N., Richeson, J. A., \& Salvatore, J. (2004). Expecting to be the target of prejudice: Implications for interethnic interactions. Personality and Social Psychology Bulletin, 31, 1189-1202.

Sherman, D. K., \& Cohen, G. L. (2006). The psychology of self-defense: Self-affirmation theory. In M. P. Zanna (Ed.), Advances in experimental social psychology (Vol. 38, pp. 183-242). San Diego, CA: Academic Press.

Sinclair, S., Lowery, B. S., Hardin, C. D., \& Colangelo, A. (2005). Social tuning of automatic racial attitudes: The role of affiliative motivation. Journal of Personality and Social Psychology, 89, 583-592.

Smart Richman, L., Pek, J., Malone, P., Siegler, I. C., \& Williams, R. B. (2008). Perceived discrimination and depression: An examination of underlying variables. Manuscript submitted for publication.

Snapp, C. M., \& Leary, M. R. (2001). Hurt feelings among new acquaintances: Moderating effects of interpersonal familiarity. Journal of Personal and Social Relationships, 18, 315-326.

Solomon, R. S. (1990). A passion for justice: Emotions and the origins of the social contract. Reading, MA: Addison-Wesley.

Sommer, K. (2001). Coping with rejection. In M. R. Leary (Ed.), Interpersonal rejection (pp. 167-188). New York: Oxford University Press.

Srivastava, S., \& Beer, J. S. (2005). How self-evaluations relate to being liked by others: Integrating sociometer and attachment perspectives. Journal of Personality and Social Psychology, 89, 966-977.

Steele, C. M. (1997). A threat in the air: How stereotypes shape intellectual identity and performance. American Psychologist, 52, 613-629.

Steele, C. M. (1998). The psychology of self-affirmation: Sustaining the integrity of the self. In L. Berkowitz (Ed.), Advances in experimental social psychology (Vol. 21, pp. 261-302). New York: Academic Press.

Storm, C., \& Storm, T. (1987). A taxonomic study of the vocabulary of emotion. Journal of Personality and Social Psychology, 53, 805-816.

Strelan, P. (2007). Who forgives others, themselves, and situations? The roles of narcissism, guilt, self-esteem, and agreeableness. Personality and Individual Differences, 42, 259-269.

Tangney, J. P. (2003). Self-relevant emotions. In M. R. Leary \& J. P. Tangney (Eds.), Handbook of self and identity (pp. 384-400). New York: Guilford Press.

Tangney, J. P., Miller, R. S., Flicker, L., \& Barlow, D. H. (1996). Are shame guilt, and embarrassment distinct emotions? Journal of Personality and Social Psychology, 70, 1256-1269.

Tangney, J. P., Wagner, P. E., Fletcher, C., \& Gramzow, R. (1992). Shamed into anger? The relation of shame and guilt to anger and self-reported aggression. Journal of Personality and Social Psychology, 62, 669-675.

Taylor, S. E. (2007). Social support. In H. S. Friedman \& R. C. Silver (Eds.), Foundations of health psychology (pp. 145-171). New York: Oxford University Press.

Taylor, S. E., Falke, R. L., Shoptaw, S. J., \& Lichtman, R. R. (1986). Social support, support groups, and the cancer patient. Journal of Consulting and Clinical Psychology, 54, 608-615.

Thibault, J. W., \& Kelley, H. H. (1959). The social psychology of groups. New Brunswick: Transaction.

Tropp, L. R., \& Wright, S. C. (2003). Evaluations and perceptions of self, ingroup, and outgroup: Comparisons between Mexican-American and European-American children. Self and Identity, 2, 203-221.

Twenge, J. M., Baumeister, R. F., DeWall, C. N., Ciarocco, N. J., \& Bartels, J. M. (2007). Social exclusion decreases prosocial behavior. Journal of Personality and Social Psychology, 92, 56-66.

Twenge, J. M., Baumeister, R. F., Tice, D. M., \& Stucke, T. S. (2001). If you can't join them, beat them: Effects of social exclusion on aggressive behavior. Journal of Personality and Social Psychology, 81, 1058-1069.

Twenge, J. M., Catanese, K. R., \& Baumeister, R. F. (2002). Social exclusion causes self-defeating behavior. Journal of Personality and Social Psychology, 83, 606-615.

Twenge, J. M., Catanese, K. R., \& Baumeister, R. F. (2003). Social exclusion and the deconstructed state: Time perception, meaninglessness, lethargy, lack of emotion, and self-awareness. Journal of Personality and Social Psychology, 85, 409-423.

Ussher, J., Kirsten, L., Butow, P., \& Sandoval, M. (2006). What do cancer support groups provide which other supportive relationships do not? The experience of peer support groups for people with cancer. Social Science \& Medicine, 62, 2565-2576.

Van Beest, I., \& Williams, K. D. (2006). When inclusion costs and ostracism pays, ostracism still hurts. Journal of Personality and Social Psychology, 91, 918-928.

Vandevelde, L., \& Miyahara, M. (2005). Impact of group rejections from a physical activity on physical self-esteem among university students. Social Psychology of Education, 8, 65-81.

Vangelisti, A. L. (2001). Making sense of hurtful interactions in close relationships: When hurt feelings create distance. In V. Manusov \& J. H. Harvey (Eds.), Attribution, communication behavior, and close relationships: Advances in personal relations (pp. 38-58). New York: Cambridge University Press.

Vangelisti, A. L., \& Young, S. L. (2000). When words hurt: The effect of perceived intentionality on interpersonal relationships. Journal of Social and Personal Relationships, 17, 393-424.

Vangelisti, A. L., Young, S. L., Carpenter-Theune, K., \& Alexander, A. L. (2005). Why does it hurt? The perceived causes of hurt feelings. Communication Research, 32, 443-477.

Waldrip, A., \& Jensen-Campbell, L. (2007). Why do I feel so bad after being excluded? The mediational effects of threatened needs on social exclusion. Manuscript submitted for publication.

Walton, G. M., \& Cohen, G. L. (2007). A question of belonging: Race, social fit, and achievement. Journal of Personality and Social Psychology, 92, 82-96.

Warburton, W. A., Williams, K. D., \& Cairns, D. R. (2006). When ostracism leads to aggression: The moderating effects of control deprivation. Journal of Experimental Social Psychology, 42, 213-220.

Williams, D. R., Neighbors, H. W., \& Jackson, J. S. (2003). Racial/ethnic discrimination and health: Findings from community studies. American Journal of Public Health, 93, 200-208.

Williams, D. R., Spencer, M. S., \& Jackson, J. S. (1999). Race, stress, and 
physical health: The role of group identity. In R. J. Contrada \& R. D. Ashmore (Eds.), Self, social identity, and physical health: Interdisciplinary explorations (pp. 71-100). New York: Oxford University Press.

Williams, K. D. (1997). Social ostracism. In R. M. Kowalski (Ed.), Aversive interpersonal behaviors (pp. 133-170). New York: Plenum Press.

Williams, K. D. (2001). Ostracism: The power of silence. New York: Guilford Press.

Williams, K. D. (2007). Ostracism. Annual Review of Psychology, 58, 425-452.

Williams, K. D., Cheung, C. K. T., \& Choi, W. (2000). Cyberostracism: Effects of being ignored over the Internet. Journal of Personality and Social Psychology, 79, 748-762.

Williams, K. D., Forgas, J. P., \& von Hippel, W. (2005). The social outcast: Ostracism, social exclusion, rejection, and bullying. New York: Psychology Press.
Williams, K. D., Govan, C. L., Croker, V., Tynan, D., Cruickshank, M., \& Lam, A. (2002). Investigations into differences between social- and cyberostracism. Group Dynamics: Theory, Research, and Practice, 6, $65-77$.

Williams, K. D., \& Sommer, K. L. (1997). Social ostracism by one's coworkers: Does rejection lead to loafing or compensation? Personality and Social Psychology Bulletin, 23, 693-706.

Zadro, L., Williams, K. D., \& Richardson, R. (2005). Riding the "O"' train: Comparing the effects of ostracism and verbal dispute on targets and sources. Group Processes and Intergroup Relations, 8, 125-143.

Received December 18, 2007

Revision received December 30, 2008

Accepted December 31, 2008

\section{Members of Underrepresented Groups: Reviewers for Journal Manuscripts Wanted}

If you are interested in reviewing manuscripts for APA journals, the APA Publications and Communications Board would like to invite your participation. Manuscript reviewers are vital to the publications process. As a reviewer, you would gain valuable experience in publishing. The $\mathrm{P} \& \mathrm{C}$ Board is particularly interested in encouraging members of underrepresented groups to participate more in this process.

If you are interested in reviewing manuscripts, please write APA Journals at Reviewers@apa.org. Please note the following important points:

- To be selected as a reviewer, you must have published articles in peer-reviewed journals. The experience of publishing provides a reviewer with the basis for preparing a thorough, objective review.

- To be selected, it is critical to be a regular reader of the five to six empirical journals that are most central to the area or journal for which you would like to review. Current knowledge of recently published research provides a reviewer with the knowledge base to evaluate a new submission within the context of existing research.

- To select the appropriate reviewers for each manuscript, the editor needs detailed information. Please include with your letter your vita. In the letter, please identify which APA journal(s) you are interested in, and describe your area of expertise. Be as specific as possible. For example, "social psychology" is not sufficient-you would need to specify "social cognition" or "attitude change" as well.

- Reviewing a manuscript takes time (1-4 hours per manuscript reviewed). If you are selected to review a manuscript, be prepared to invest the necessary time to evaluate the manuscript thoroughly. 